\title{
POLYGONACEAE DA CADEIA DO ESPINHAÇO, BRASIL ${ }^{1}$
}

\author{
Efigênia de Melo
}

Recebido em 28/09/1999. Aceito em 02/05/2000

\begin{abstract}
RESUMO - (Polygonaceae da Cadeia do Espinhaço, Brasil). O estudo da família Polygonaceae é parte do projeto "Estudos de flora e fauna na Cadeia do Espinhaço, Bahia, Brasil". Neste trabalho a área de estudo foi ampliada, abrangendo também as espécies da Cadeia do Espinhaço do Estado de Minas Gerais. A família está representada na área por cinco gêneros, com os respectivos números de espécies: Coccoloba (14): C. acrostichoides, C. alagoensis, C. alnifolia, C. brasiliensis, C. cereifera, C. fastigiata, C. lucidula, C. ochreolata, C. pipericarpa, C. salicifolia, C. scandens, C. schwackeana, C. striata e C. warmingii, Polygonum (6): P. acuminatum, P. ferrugineum, P. hispidum, P. hydropiperoides, P. meisnerianum e P. punctatum, Rumex (1): R. crispus, Ruprechtia (1): R. apetala e Triplaris (1): T. gardneriana. São apresentadas chaves para os gêneros e espécies, bem como descrições, ilustrações, comentários sobre a distribuição geográfica, fenologia e variabilidade para todos os táxons.
\end{abstract}

Palavras-chave - Polygonaceae, florística, "Cadeia do Espinhaço”, campo rupestre, Bahia, Minas Gerais

\begin{abstract}
Polygonaceae of the "Cadeia do Espinhaço", Brazil). The study of the family Polygonaceae is a part of the project "Study of the flora and fauna of the Espinhaço Range region, Bahia, Brazil". In this paper we are including the species of the Espinhaço Range of Minas Gerais State. In that area the family is represented by the following genera, with respective number of species: Coccoloba (14): C. acrostichoides, C. alagoensis, C. alnifolia, C. brasiliensis, C. cereifera, C. fastigiata, C. lucidula, C. ochreolata, C. pipericarpa, C. salicifolia, C. scandens, $C$. schwackeana, C. striata and C. warmingii, Polygonum (6): P. acuminatum, P. ferrugineum, P. hispidum, $P$. hydropiperoides, P. meisnerianum and P. punctatum, Rumex (1): R. crispus, Ruprechtia (1): $R$. apetala and Triplaris (1): T. gardneriana. Key to the genera and species, descriptions and illustrations, as well as comments on the geographic distribution, phenology and variability of the species are presented.
\end{abstract}

Key words - Polygonaceae, floristic, Espinhaço range, Campo rupestre, Bahia, Minas Gerais

\section{Introdução}

A Cadeia do Espinhaço possui 6.000$7.000 \mathrm{~km}^{2}$ de extensão nos Estados da Bahia e de Minas Gerais. Ao sul, inicia-se nas proximidades de Belo Horizonte, atravessa todo o Esta- do de Minas Gerais e penetra no Estado da Bahia, onde passa a se chamar Chapada Diamantina. Corre a leste do Rio São Francisco, até as proximidades de Juazeiro, ao norte do Estado. O limite sul da Cadeia é a Serra do Ouro Branco, nas proximidades de Belo Horizonte (20³5'S)

\footnotetext{
Projeto parcialmente financiado pelo $\mathrm{CNPq}$

2 Departamento de Ciências Biológicas, Universidade Estadual de Feira de Santana, Km 3, BR-116 Norte, Câmpus Universitário, C. Postal 294, CEP 44031-460, Feira de Santana, Bahia, Brasil. e-mail: efidemelo@ hotmail.com
} 
e o limite norte situa-se nas Serras do São Francisco, no Município de Sento Sé, ao norte da Bahia, nas proximidades de Juazeiro (443' $\mathrm{W}$ ). As cotas altimétricas variam entre 900 e $2.000 \mathrm{~m}$. As serras que compõem esse complexo constituem importantes centros de diversidade biológica e endemismo. São reconhecidas seis grandes áreas, em Minas Gerais: Serra do Ouro Branco, Serra da Piedade, Serra do Caraça, Serra do Cipó, Serra do Cabral e Serra de Grão-Mogol, e na Bahia, Serra do Rio de Contas (Pico das Almas), Serra do Sincorá, Serra do Tombador e Serra de Jacobina (Davis et al. 1997) (Fig. 1).

$\mathrm{Na}$ Cadeia do Espinhaço predomina vegetação típica de campos rupestres, no entanto, outros tipos de vegetação são encontrados na área, tais como as matas de galeria, os campos cerrados entre altitudes de 860 a $1.000 \mathrm{~m}$, entremeados com os campos rupestres. Nas porções basais da Chapada Diamantina, predominam as caatingas e as matas estacionais, em altitudes acima de 500m. Essas terras baixas representam barreira para a migração da flora entre os dois Estados. Os diversos tipos de vegetação, em geral, não são contínuos, e apresentam-se sob a forma de ilhas, manchas ou capões rodeados de campos rupestres ou às margens de rios, em longos cordões florestais.

A família Polygonaceae possui cerca de 40 gêneros, com mais de 800 espécies distribuídas nas regiões tropicais, temperadas e subtropicais (Barroso et al. 1978). No Brasil sete gêneros têm ocorrência espontânea, sendo Coccoloba o mais representativo, com 44 espécies (Howard 1961).

Poucos trabalhos referem-se às espécies de Polygonaceae da Cadeia do Espinhaço: Harley \& Simmons (1980), em levantamento da flora da Bahia, citam Coccoloba brasiliensis Nees \& Mart., Polygonum acuminatum Kunth, $P$. hispidum Kunth e P. punctatum Elliott. Howard (1995) menciona Coccoloba brasiliensis para o Pico das Almas; Ribeiro (1997) discute a dinâmica de populações de Coccoloba cereifera Schwacke, espécie endêmica da Serra do Cipó, Minas Gerais.
Este trabalho tem como objetivo fornecer maiores informações sobre a ocorrência da família Polygonaceae no Brasil, bem como contribuir para o conhecimento da flora dos campos rupestres, da Chapada Diamantina e da Cadeia do Espinhaço.

\section{Material e métodos}

Foram analisadas amostras dos seguintes Herbários, de acordo com o Index Herbariorum, Holmgren et al. (1990): ALCB, B, BHCB, CEN, CEPEC, ESA, HUEFS, HRB, IPA, K, MBM, MG, NY, PEUFR, R, RB, SP, SPF, UB e VIC. Todas as amostras que serviram de base para as ilustrações estão depositadas no Herbário da Universidade Estadual de Feira de Santana (HUEFS). A nomenclatura para os frutos de Polygonaceae segue Spjut (1994).

\section{Resultados e discussão}

Os indivíduos da família Polygonaceae são constituídos por ervas, arbustos, trepadeiras, lianas ou árvores, monóicas ou dióicas; ramos articulados, nodosos, medula maciça ou fistulosa. Folhas alternas, espiraladas, simples, estípulas concrescidas (ócreas) caducas ou persistentes, membranáceas a coriáceas, nervação broquidódroma. Inflorescências racemosas, paniculadas ou em fascículos, terminais ou subterminais, brácteas e bractéolas (ocréolas) persistentes. Flores hipóginas, bissexuadas ou unissexuadas por redução do sexo abortado, actinomorfas; sépalas e pétalas idênticas, (4)58(9), imbricadas, livres a unidas na base, persistentes; estames 5-9, livres a unidos na base, anteras bitecas, rimosas, basifixas ou dorsifixas; ovário súpero, 2-3(4) carpelar, unilocular, uniovular, placentação basal; estiletes 2-3(4), livres ou unidos na base, estigmas lobados, fimbriados ou capitados. Fruto simples, indeiscente, envolvido pelo perianto acrescente e persistente, carnoso (acrossarco) ou seco, membranáceo, alado (pseudosâmara) ou não alado (diclésio). 


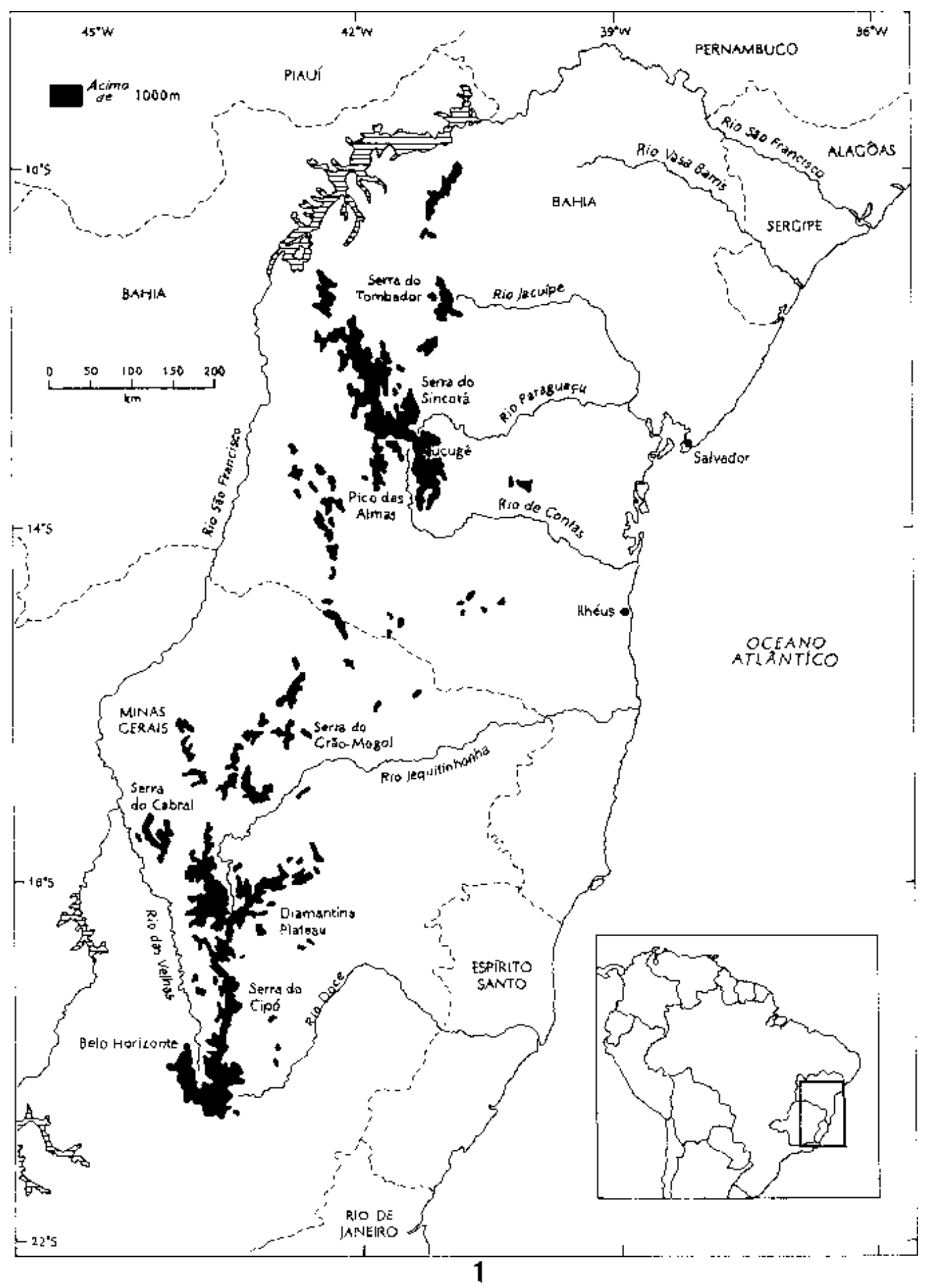

Figura 1. Mapa da Cadeia do Espinhaço (Davis et al. 1997). 
Na Cadeia do Espinhaço ocorrem cinco gêneros de Polygonaceae, dos quais Coccoloba é o mais representativo, com 14 espécies: $C$. acrostichoides, C. alagoensis, C. alnifolia, $C$. brasiliensis, C. cereifera, $C$. fastigiata, $C$. lucidula, C. ochreolata, C. pipericarpa, C. salicifolia, C. scandens, C. schwackeana, C. striata e $C$. warmingii. Em seguida vem o gênero Polygonum, com seis espécies: $P$. acuminatum, $P$. ferrugineum, $P$. hispidum, $P$. hydropiperoides, $P$. meisnerianum e $P$. punctatum. Os demais gêneros são representados por uma única espécie: Rumex crispus, Ruprechtia apetala e Triplaris gardneriana. Coccoloba cereifera ocorre exclusivamente nos campos rupestres da Serra do Cipó, em Minas Gerais, e Coccoloba acrostichoides ocorre nos campos rupestres e nas matas exclusivamente na Cadeia do Espinhaço, em Minas Gerais. É necessário maior número de coletas em toda a extensão da Cadeia do Espinhaço para se conhecer melhor a fenologia e a distribuição de cada espécie ao longo da cadeia montanhosa.

Chave para os gêneros de Polygonaceae da Cadeia do Espinhaço

1. Ervas ou subarbustos, fruto diclésio, perianto frutífero seco

2. Perianto frutífero livre, não aderente ao pericarpo 3. Rumex

2 Perianto frutífero ligado na base até a metade ou acima, aderente ao pericarpo

1. Árvores, arbustos ou lianas, fruto pseudosâmara ou acrossarco, perianto frutífero seco ou carnoso

3. Fruto pseudosâmara, alas membranáceas, duas ou mais vezes o comprimento do pericarpo

4. Tubo do perianto inteiro, encobrindo o fruto 5. Triplaris

4. Tubo do perianto partido, expondo o fruto 4. Ruprechtia

3. Fruto acrossarco, perianto frutífero carnoso

1. Coccoloba
Coccoloba P. Browne ex L., Syst. Nat. Ed. 10, 2: 1007.1759.

Árvores, arbustos ou lianas, monóicos ou dióicos. Folhas membranáceas ou coriáceas, margem lisa; ócrea tubulosa, persistente ou caduca. Inflorescências racemosas simples, raro ramificadas. Flores diminutas envolvidas por ocréola e bráctea; perianto 5-partido, tepalóide, unido na base, formando hipanto; androceu 7-8 estames, filetes de base conata, alargada, anteras dorsifixas, versáteis; estiletes curtos, estigmas lobados ou capitados; flores estaminadas com lobos patentes e androceu excluso; flores pistiladas com lobos eretos, androceu incluso e gineceu excluso. Fruto acrossarco.

Comentários: o gênero Coccoloba possui cerca de 400 espécies distribuídas essencialmente na região Neotropical (Brandbyge 1990). No Brasil ocorrem cerca de 44 espécies (Howard 1961).

Chave para a identificação das espécies de Coccoloba da Cadeia do Espinhaço

1. Perianto frutífero membranáceo, folhas de base aguda, nunca cordada

2. C. alagoensis

1. Perianto frutífero coriáceo, folhas muito variáveis, freqüentemente de base cordada

2. Pecíolo inserido na base ou acima da base da ócrea

3. Fruto oblongo, face abaxial glabra ..... 5. C. cereifera

3. Fruto oval a arredondado

4. Face abaxial da folha pubescente

5. Folhas rigidamente coriáceas, pecíolo inserido na base da ócrea ...... 1. C. acrostichoides

5. Folhas membranáceas ou subcoriáceas, pecíolo inserido acima da base da ócrea.......

6. C. fastigiata

4. Face abaxial da folha glabra

6. Glândulas punctiformes conspícuas na face abaxial 
7. Comprimento da lâmina foliar menor ou igual a $6 \mathrm{~cm}$ 9. C. pipericarpa

7. Comprimento da lâmina foliar maior que $6 \mathrm{~cm}$.

8. Ócreas íntegras ao menos nas bases

3. C. alnifolia

8. Ócreas não íntegras

9. Ócreas escariosas, com nervuras persistentes

13. C. striata

9. Ócreas marcescentes sem nervuras persistentes

7. C. lucidula

6. Glândulas punctiformes inconspícuas 14. C. warmingii

2. Pecíolo inserido abaixo da base da ócrea 10. Glândulas punctiformes inconspícuas 10. C. salicifolia

10. Glândulas punctiformes conspícuas na face abaxial

11. Ocréolas maiores que as brácteas

8. C. ochreolata

11. Ocréolas de tamanho igual ao das brácteas

12. Face abaxial das folhas pubescentes ou pubérula 11. C. scandens

12. Face abaxial das folhas glabras 4. C. brasiliensis

1. Coccoloba acrostichoides Cham., Linnaea 8:132-133. 1833.

Fig. 2-7

Arbusto ereto, densamente ramificado 0,4$3 \mathrm{~m}$ alt.; ramos com casca fissurada, ápices pubescentes, lenticelas inconspícuas, internós maciços, curtos, $2-5 \mathrm{~cm}$. Folhas dos ramos vegetativos ca. $20 \times 11 \mathrm{~cm}$, folhas dos ramos férteis, 2-8x1-3,5cm, lâmina oblonga, ápice obtuso a arredondado, base obtusa, truncada, subcordada a fortemente cordada, margem revoluta, coriácea, pubescente na face abaxial, glabra na adaxial, glândulas punctiformes inconspícuas, nervação profundamente marcada na face adaxial, fortemente proeminente na abaxial; ócrea $0,5-1 \mathrm{~cm}$, coriácea, pubescente, base persistente; pecíolo $0,2-1,5 \mathrm{~cm}$, pubescente, inserido na base da ócrea. Racemos densifloros, $5-10 \mathrm{~cm}$, raque pubescente, costada, pedicelos 1$3 \mathrm{~mm}$, brácteas e ocréolas ca. $1 \mathrm{~mm}$, coriáceas, pubescentes. Flores 1-2mm. Perianto frutífero 5-8mm, oval a arredondado, coriáceo, lobos aderidos; pedicelos frutíferos $2-4 \mathrm{~mm}$ compr.

Comentários: restrita ao Estado de Minas Gerais. Na área de estudo foi coletada no campo rupestre e na mata, em altitudes que variam entre 1.100 e $1.300 \mathrm{msnm}$. Espécimes da mata atingem porte muito maior que as do campo rupestre, com folhas de até $25 \times 12 \mathrm{~cm}$. Distinguese de Coccoloba brasiliensis pela pubescência densa da face abaxial das folhas. Floresce e frutifica de julho a novembro.

Material examinado: BRASIL. Minas Gerais: Conceição do Mato Dentro, II/1996, Roque et al. 132 (SPF); Congonhas do Norte, Serra do Carapina (S. Talhada), N da S. do Cipó, $18^{\circ} 52^{\prime} \mathrm{S}, 43^{\circ} 44^{\prime} \mathrm{W}, 1.300 \mathrm{msnm}$, II/1998, Rapin et al. 526 (SPF); Ibidem, IV/1982, Furlan et al. CFSC 8331 (SPF); Ibidem, IV/1982, Furlan et al. CFSC 8305 (SPF); Jaboticatubas, S. do Cipó, III/1969, Eiten \& Eiten 11035 (SP); Santana do Riacho, 20/IX/1993, Campos et al. CFSC 13322 (SPF); Ibidem, X/1981, Cordeiro et al. CFSC 7519 (SPF); Ibidem, VII/1991, Giulietti et al. CFSC 12527 (SPF); Ibidem, III/1991, Pirani et al. CFSC 12080 (SPF); Ibidem, IV/1991, Pirani et al. CFSC 12275 (SPF); Ibidem, XI/1980, Cordeiro et al. CFSC 6714 (SPF); Ibidem, VI/1991, Bianchini CFSC 12802 (SPF); Ibidem, Alto Palácio, arredores da sede do IBAMA, V/1993, Souza \& Sakuragui 3338 (ESA); Ibidem, km 117, S. do Cipó, 1.200msnm, IV/1978, Martinelli 4272 (RB); Santo Antônio do Itambé, início da estrada para o Pico do Itambé, 800-1.200msnm, III/1995, Souza et al. 8392 (ESA). Serra do Espinhaço, II/1968, Irwin et al. 20497 (B). 

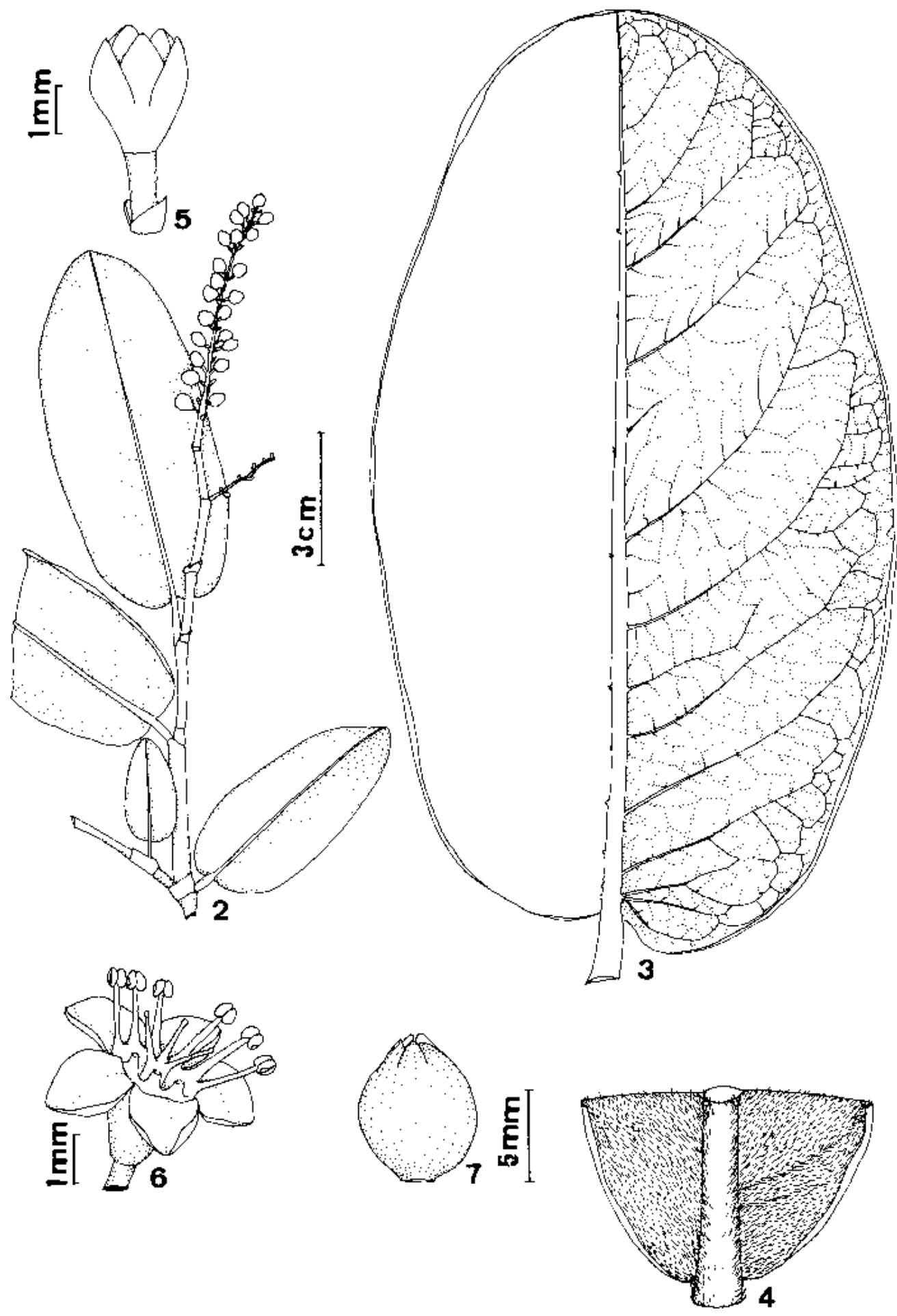

Figura 2-7. Coccoloba acrostichoides Cham. 2. hábito; 3. folha do ramo basal; 4. detalhe da face abaxial; 5. flor fechada; 6. flor; 7. fruto (França et al. 2595, 2602 e 2608). 
2. Coccoloba alagoensis Wedd., Ann. Sci. Nat. III. 13: 260. 1849.

Fig. 8-10

Arbusto ereto, densamente ramificado até $3 \mathrm{~m}$ alt.; ramos com casca acinzentada, aderida, glabros, lenticelas oblongas, alvas, internós maciços, curtos, $1-4 \mathrm{~cm}$. Folhas dos ramos vegetativos não observadas, folhas dos ramos férteis 5-10x3-6cm, lâmina elíptica a oblonga, ápice agudo ou obtuso, base aguda, raro subarredondada, margem plana, membranácea a subcoriácea, glabra, tricomas remanescentes nas axilas das nervuras da face abaxial, glândulas punctiformes visíveis na face abaxial, nervação impressa em ambas as faces; ócrea 0,5-1 cm, membranácea, glabra, com pontos glandulosos; pecíolo $0,5-1,5 \mathrm{~cm}$, glabro, inserido abaixo da base da ócrea. Racemos densifloros, 4-10cm, raque glabra, estriada, pedicelos ca. $1 \mathrm{~mm}$, brácteas ca. $1 \mathrm{~mm}$, glabras, ocréolas 1,5 $2 \mathrm{~mm}$, glabras. Flores 1-1,5mm. Perianto frutífero $5-7 \mathrm{~mm}$, oval ou trígono-ovalado, membranáceo, marcescente, lobos livres, imbricados; pedicelos frutíferos finos, 2-3mm compr.

Comentários: citada para os Estados de Alagoas, Bahia, Minas Gerais, Rio de Janeiro (Howard 1961) e Mato Grosso do Sul (nova ocorrência). Espécie pouco representada nas coleções dos herbários estudados. O pequeno número de coletas não permitiu a definição do período fenológico.

Material examinado: BRASIL. Bahia: Gentio do Ouro, Santo Inácio, II/1977, Harley 19082 (CEPEC, HRB, K, MBM).

Material adicional examinado: BRASIL. Bahia: Barra, Ibiraba, II/1997, Queiroz 4847 (HUEFS); Xique-Xique, dunas do S. Francisco, 1047'16" S 4246'22" W, 548msnm, VI/1996, PCD 2988 (CEPEC, HUEFS). Mato Grosso do Sul: Ladário, II/1995, Damasceno 455 (HUEFS); Corumbá, VII/1996, Rego 699 (HUEFS).

3. Coccoloba alnifolia Casar., Nov. Stirp. Bras. 8: 71. 1844.
Fig. 11-14

Arbusto a árvore de 2-20m alt.; ramos com casca fissurada, ápices glabros, lenticelas oblongas a fusiformes, alvas, internós maciços, curtos, $2-5 \mathrm{~cm}$. Folhas dos ramos vegetativos $25-$ $40 \times 20-45 \mathrm{~cm}$, folhas dos ramos férteis $6-15 \times 4-$ $14 \mathrm{~cm}$, lâmina obovada a sub-arredondada, ápice curto-acuminado a arredondado, base obtusa, arredondada a subcordada, margem revoluta, coriácea, face adaxial glabra, abaxial com pilosidade remanescente nas axilas ou ao longo das nervuras, glândulas punctiformes visíveis na face abaxial, nervação marcada na face adaxial e proeminente na abaxial; ócrea 1-2cm, coriácea, glabra ou com pilosidade remanescente, base persistente; pecíolo $0,5-1,5 \mathrm{~cm}$, inserido acima da base da ócrea. Racemos densifloros, 10-30cm, raque estriada, pubérula, pedicelos ca. $1 \mathrm{~mm}$, brácteas e ocréolas 1,5-2mm, glabras. Flores 1$1,5 \mathrm{~mm}$. Perianto frutífero $3-6 \mathrm{~mm}$, oval ou elíptico, coriáceo, lobos livres; pedicelos frutíferos 2-4mm compr.

Comentários: ocorre na restinga e mata atlântica (Rizzini 1986). É distribuída nos Estados do Rio de Janeiro, Bahia, Pernambuco e Minas Gerais (Rizzini 1978). É uma das poucas espécies que pode atingir até $20 \mathrm{~m}$ alt. Encontrada também nas matas estacionais, transição entre a mata atlântica e a caatinga e nas margens dos rios, formando densas populações arbustivas na planície arenosa do rio Paraguaçu e outros rios nas bordas da Chapada Diamantina. Ocorre em altitudes que variam entre $150 \mathrm{e}$ $350 \mathrm{msnm}$. Floresce e frutifica de janeiro a junho.

Material examinado: BRASIL. Bahia: Andaraí/Lençóis, Remanso/Maribus, I/1997, Guedes et al. PCD 4628 (ALCB, CEPEC, HUEFS); Rio Santo Antônio, VI/1984, Hatschbach 48071 (CEPEC, HUEFS); Ibidem, IV/1996, 330msnm, França et al. 1584 (HUEFS); Ibidem, 4km de Andaraí, estrada para BR-242, Rio Santo Antônio, 12 45'15" S 41 ${ }^{\circ}$ 19'44”' W, 320msnm, II/1999, França et al. 2644 (HUEFS). 


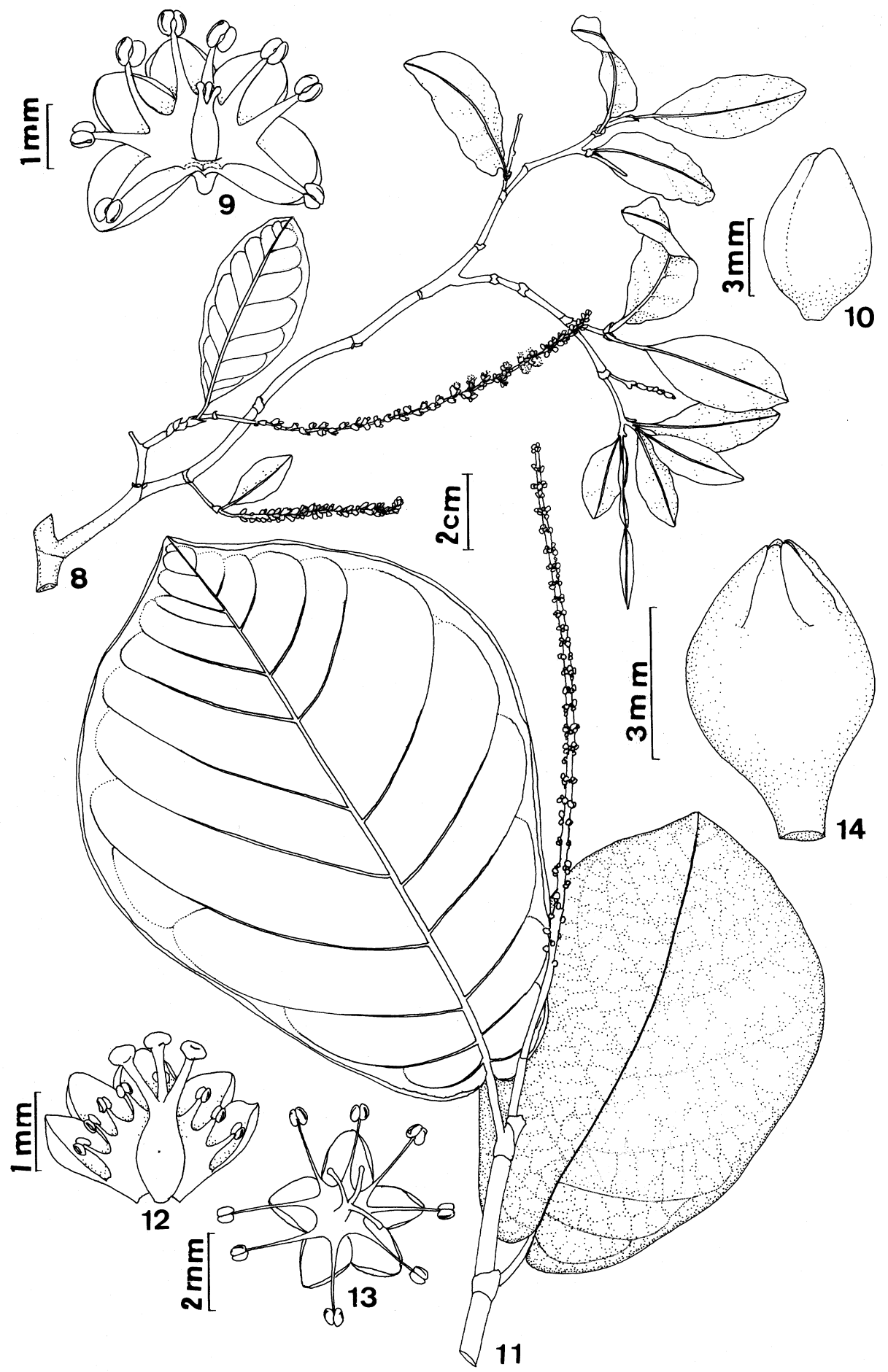

Figura 8-14. Coccoloba. 8-10. C. alagoensis Wedd. 8. hábito, 9. flor; 10. fruto (Queiroz 4847, Rego 699); 11-14. C. alnifolia Casar; 11. hábito; 12. flor pistilada; 13. flor estaminada; 14. fruto (Mattos Silva \& Santos 809, Guedes PCD 4628). 
Material adicional examinado: BRASIL. Bahia: Nova Viçosa, V/1980, Mattos Silva \& Santos 809 (HUEFS); Porto Seguro, Carvalho et al. 1251 (HUEFS); Trancoso, 16²6'S 39³'W, XI/1997, Lombardi, 1594 (HUEFS); Itaberaba, Rio Paraguaçu, VI/1995, França et al. 1217 (HUEFS).

4. Coccoloba brasiliensis Nees \& Mart., Nov. Act. Acad. Nat. Cur. 11: 30. 1823.

Fig. 15-17

Arbusto ereto, densamente ramificado, até $3 \mathrm{~m}$ alt.; ramos com casca fissurada, glabros, lenticelas elípticas, marrons, internós maciços, curtos, $2-5 \mathrm{~cm}$. Folhas dos ramos basais 15-25x9$14 \mathrm{~cm}$, folhas dos ramos férteis $4-8 \times 3-5 \mathrm{~cm}$, lâmina oblonga, ápice obtuso a arredondado, base obtusa a subcordada até fortemente cordada, margem revoluta, coriácea, glabra, glândulas punctiformes visíveis na face abaxial, nervação inconspícua na face adaxial, proeminente na abaxial, nervação terciária pouco visível; ócrea 0,5-1cm, coriácea, glabra, com pontos glandulosos, decídua; pecíolo $0,5-2 \mathrm{~cm}$, glabro, inserido abaixo da base da ócrea. Racemos densifloros, $8-10 \mathrm{~cm}$, raque glabra, estriada, pedicelos $1-2 \mathrm{~mm}$, brácteas ca. $1,5 \mathrm{~mm}$, pubérula, ocréolas ca. 1mm, glabras. Flores 1-2mm. Perianto frutífero 4-6mm, oval, coriáceo, lobos aderidos; pedicelos frutíferos ca. $2 \mathrm{~mm}$ compr.

Comentários: ocorre em campos e cerrados, nos Estados de Mato Grosso, Bahia e Minas Gerais (Rizzini 1986). Na área de estudo é muito freqüente a altitudes que variam entre 990 e $1.350 \mathrm{msnm}$; raramente ocorre nas caatingas e zonas transicionais abaixo de $700 \mathrm{msnm}$. Floresce e frutifica de fevereiro a junho e de setembro a dezembro.

Material examinado: BRASIL. Bahia: Mucugê, caminho para Guiné, 12 ${ }^{\circ} 56^{\prime}$ 23" S 41'28'31" W, 1.040msnm, II/1997, Guedes et al. PCD 5659 (CEPEC); Ibidem, Fda. Pedra Grande, estrada p/ Boninal 130'20" S 41'33'48" W, 990msnm, II/1997, Atkins et al. PCD 5825 (HUEFS); Rio de Contas, próximo a Barragem

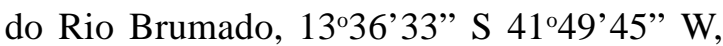
990msnm, I/1998, França \& Castro (HUEFS); Ibidem, Serra Marcelino, 1335'43" S 41 50'05" W, 1.170msnm, II/1997, Saar et al. PCD 4891 (CEPEC, HUEFS); Ibidem, $3 \mathrm{~km}$ NE da cidade de Rio de Contas, estrada para Jussiape, $1.090 \mathrm{msnm}, 13^{\circ} 34^{\prime} \mathrm{S} 41^{\circ} 50^{\prime} \mathrm{W}$, III/1988, Ginzbarg et al. 882 (CEPEC, HUEFS); Ibidem,

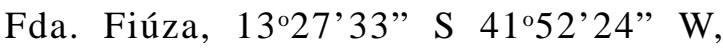
$1.130 \mathrm{msnm}, \mathrm{II} / 1997$, Stannard et al. PCD 5069 (HUEFS); Ibidem, Melo et al. 2637 (HUEFS). Minas Gerais: Santana do Riacho, $18^{\circ} 55^{\prime} \mathrm{S}$, $43^{\circ} 54^{\prime} W$. Fda. Inhame (Serra Mineira), Serra do Cipó, III/1982, Cordeiro et al. CFSC 8200 (SPF); Ibidem, III/1982, Pirani et al. CFSC 8029 (SPF); Ibidem, III/1982, Cordeiro et al. CFSC 8199 (SPF).

Material adicional examinado: BRASIL. Bahia: Vitória da Conquista, IV/1995, Melo \& França 1233 (HUEFS).

5. Coccoloba cereifera Schwacke, Pl. Nov. Mineir. 1: 7. 1898.

Fig. 18-20

Arbusto pendente, esparsamente ramificado, até $2 \mathrm{~m}$ alt.; ramos com casca finamente aderida, glabros, lenticelas elípticas, esparsas, internós maciços, curtos, $1,5-4 \mathrm{~cm}$. Folhas dos ramos vegetativos e férteis sem diferenciação de tamanho, lâmina oblonga a oblongolanceolada, 5-20x4-8cm, ápice obtuso a arredondado, base obtusa, truncada ou subcordada, margem revoluta, fortemente coriácea, glabra, glândulas punctiformes não visíveis, nervação bem marcada na face adaxial, proeminente na abaxial; ócrea 1-3cm, coriácea, glabra, base persistente; pecíolo $0,5-1,5 \mathrm{~cm}$, glabro, inserido na base ou acima da base da ócrea. Racemos densifloros, pêndulos, $10-35 \mathrm{~cm}$, ocasionalmente formando cincinos escorpióides, raque glabra, costada, pedicelos 1-2mm, brácteas e ocréolas ca. $2 \mathrm{~mm}$, coriáceas, glabras. Flores 1,5-2,5mm. Perianto frutífero $0,7-1 \mathrm{~cm}$, oblongo, coriáceo, lobos livres, imbricados; pedicelos frutíferos $2 \mathrm{~mm}$ compr. 
Comentários: espécie endêmica da Serra do Cipó (Minas Gerais). Floresce e frutifica de abril a julho. Espécie de fácil reconhecimento por apresentar folhas verde-acinzentadas, verdeazuladas e até verde-vináceas, destacando-se da vegetação ao redor.

Material examinado: BRASIL. Minas Gerais: Jaboticatubas, III/1969, Eiten \& Eiten 11097 (UB); Santana do Riacho, Conceição do Mato Dentro, VII/1987, Pirani et al. CFSC 10268 (SPF); Ibidem, Serra do Cipó, XI/1965, Tryon \& Tryon 6801 (NY); Ibidem, XI/1965, Eiten \& Eiten 6786 (NY); Ibidem, entre o Chapéu de Sol e a fazenda Palácio, estrada para Lagoa Santa/Conceição do Mato Dentro, km 115, X/1981, Martins et al. 1256 (VIC); Ibidem, km 115, X/1981, Martins et al. 7192 (VIC); Ibidem, km 130, XI/1952 (VIC); Ibidem, III/1983, Kawasaki et al. CFSC 9112 (SPF); Ibidem, após a estrada para Usina de força em direção ao córrego "duas pontinhas", IV/1995, MelloSilva et al. 1036 (SPF); Ibidem, km 115, Rod. Belo Horizonte/Conceição do Mato Dentro, fazenda Serra do Cipó, X/1980, Pirani et al. CFSC 6581 (SPF); Ibidem, km 110, VII/1987, Pirani et al. CFSC 10268 (SPF); Ibidem, km 118, próximo a fazenda Palácio, CFSC 9112 (SPF); Ibidem, km 120, XI/1984, Longhi-Wagner et al. CFCR 5966 (SPF); Ibidem, V/1993, Sano \& Coffani Nunes CFSC 13111 (SPF); Ibidem, VIII/1980, Sakuragui, \& Souza 33 (SPF); Ibidem, XII/1979, Martinelli 6323 (RB); Ibidem, V/1974, Martinelli 294 (RB); Ibidem, VII/1977, Martinelli \& Távora 2647 (RB); Ibidem, VI/1976, Martinelli 874 (RB); Ibidem, II/1987, Costa 31 (RB); Ibidem, V/1987, Marquete et al. 51 (RB); Ibidem, III/1964, Pereira 8932 (RB); Ibidem, I/1972, Hatschbach 28851 (MBM); Ibidem, VIII/1972, Hatschbach 29994 (MBM); Ibidem, III/1958, Heringer \& Castellanos 6050 (UB); Ibidem, Hatschbach \& Ahumada 32547 (MBM); Ibidem, V/90, Arbo et al. 4126 (SPF); Ibidem, II/1972, Anderson et al. 36145 (RB); Ibidem, IV/1973, Braga 2669 (RB); Ibidem, II/1968, Irwin et al.
20057 (NY, RB); Ibidem, XI/1965, Eiten \& Eiten 6786 (NY, RB); Ibidem, III/1972, Rizzini s.n. (RB); Ibidem, I/1951, Kuhlmann 36 (RB); Ibidem, Damázio s.n. RB 269 e 227 (RB); Ibidem, km 129, XII/1949, Duarte s.n. (RB); Ibidem, Palacinho, X/1959, Travassos s.n. (RB); Ibidem, pedregoso, XII/1940, Occhioni s.n. (RB); Ibidem, km 130, XI/1952, Magalhães VIC 3749 (VIC); Serra do Cipó, campos alpinos, I/1951, Andrade-Lima 51-874 (IPA); Ibidem, V/1987, Marquete et al. 51 (HRB); Ibidem, XII/ 1959, Maguire et al. 44663 (NY); Ibidem, I/1951, Pires \& Black 2816 (NY); Serra do Espinhaço, II/1968, Irwin et al. 20057 (UB); Ibidem, II/1972, Anderson et al. 36145 (UB); Ibidem, Serra do Cipó, 19¹7'15" S, 4335'20' W, 1.100-1.200msnm, VII/1998, Stehmann \& Franceschinelli 2367 (BHCB); Ibidem, Serra do Cipó, Rodovia Belo Horizonte/Conceição do Mato Dentro, ca. $5 \mathrm{~km}$ após o Chapéu de Sol, 19¹7'11" S, 43³5'20”' W, 1.150msnm, III/1995, Souza et al. 8100 (ESA); Ibidem, km 9, VIII/ 1990, Sakuragui \& Souza 33 (ESA); Ibidem, 19¹7'58'S 4335'39'W, 1.250-1.315msnm, VII/ 1998, França et al. 2592 (HUEFS); sem localidade específica, Schwacke 11780 (B, holótipo!)

6. Coccoloba fastigiata Meisn., Fl. Bras. 5(1): 34. 1855.

Fig. 21-23

Arbusto escandente; ramos com casca aderida, ápices tomentosos, internós maciços, curtos, $2-5 \mathrm{~cm}$, lenticelas esparsas, arredondadas e fusiformes, alvas. Folhas dos ramos vegetativos não observadas, folhas dos ramos férteis 7-12x3$4,5 \mathrm{~cm}$, lâmina lanceolada a oval-lanceolada, ápice agudo a curto-acuminado, base arredondada a subcordada, margem plana, coriácea, face adaxial glabra ou pubescente, abaxial densamente pubescente ou glabrescente, glândulas punctiformes inconspícuas, nervação imersa na face adaxial e proeminente na abaxial; ócrea 0,5 $1 \mathrm{~cm}$, coriácea, densamente pubescente; pecíolo 0,5-1 cm, ferrugíneo-tomentoso, inserido acima da base da ócrea. Racemos densifloros, $5-10 \mathrm{~cm}$, 


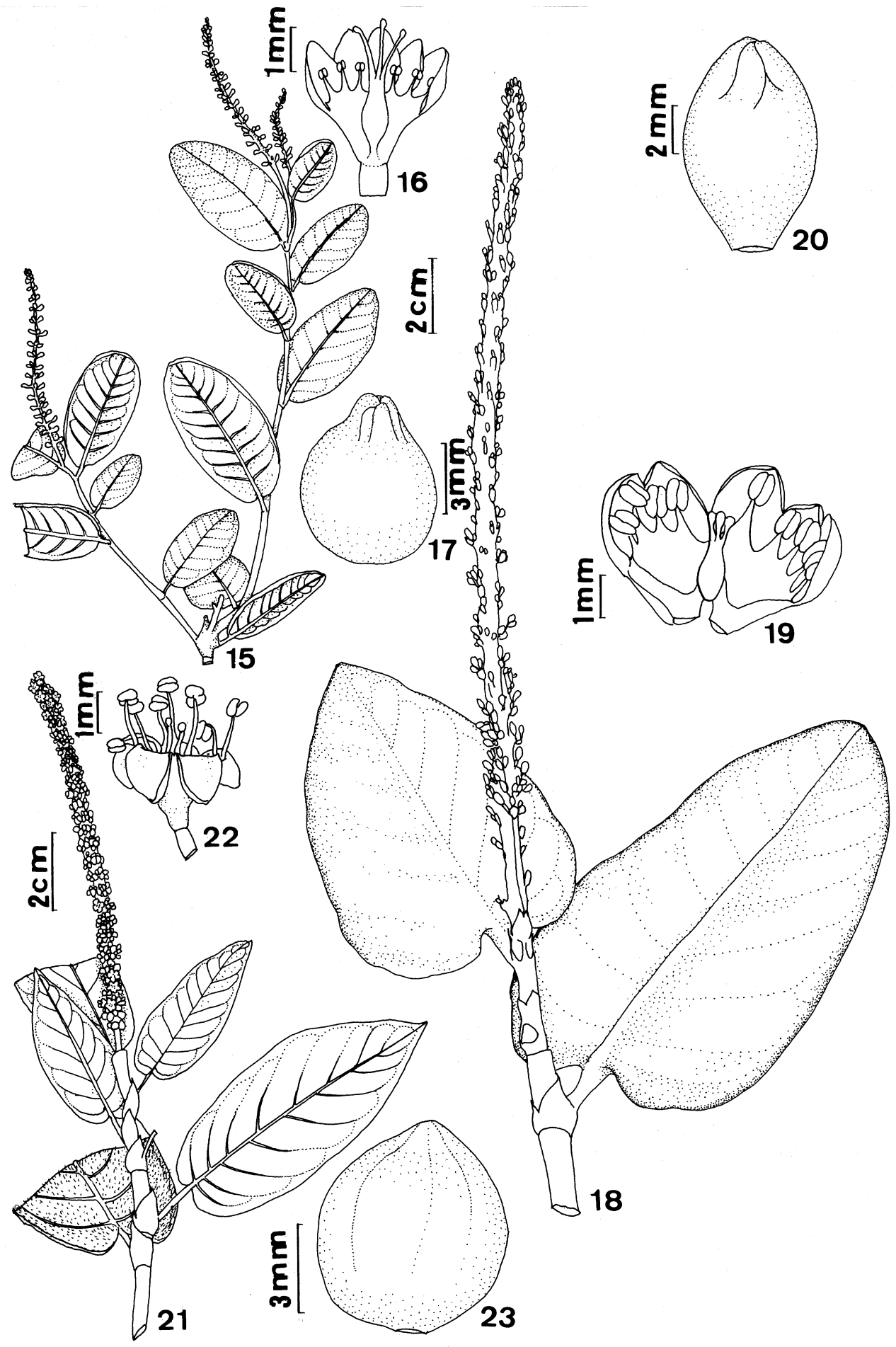

Figura 15-23. Coccoloba. 15-17. C. brasiliensis Nees \& Mart. 15. hábito; 16. flor; 17. fruto (Melo \& França 1233, Melo et al. 2637); 18-20. C. cereifera Schw.; 18. hábito; 19. flor; 20. fruto (França et al. 2592); 21-23. C. fastigiata Meisn.; 21. hábito; 22. flor; 23. fruto (Hatschbach 46566, 65165). 
raque pubescente, costada, pedicelos ca. $1 \mathrm{~mm}$, bráctea e ocréola ca. $1 \mathrm{~mm}$, pubescentes. Flores 2-3mm. Perianto frutífero 5-6mm, oval, coriáceo, lobos aderidos; pedicelos frutíferos ca. $3 \mathrm{~mm}$ compr.

Comentários: Coccoloba fastigiata ocorre no Rio de Janeiro nas restingas e mata atlântica (Rizzini 1986). Na área de estudo só foi registrada na Chapada Diamantina.

Material examinado: BRASIL. Bahia: Caetité, Chapada Diamantina, V/1983, Hatschbach 46566 (HUEFS, MBM); Paramirim, Rodovia Paramirim/Caetité, 40km N de Caetité, Hatschbach 65165 (HUEFS).

Material adicional examinado: BRASIL. Rio de Janeiro: sem localidade específica, Kuhlmann \& Brade 15750 (RB); Ibidem, Glaziou 7888 (B).

7. Coccoloba lucidula Benth., Lond. Jour. Bot. 4: 627. 1845.

Fig. 24-26

Arbusto escandente a liana; ramos com casca firmemente aderida, glabros, lenticelas orbiculares e arredondadas, alvas, evidentes; internós maciços, curtos, 1-2,5cm e longos, 10$12 \mathrm{~cm}$. Folhas dos ramos vegetativos $10-25 \times 8-$ $10 \mathrm{~cm}$, folhas dos ramos férteis $5-15 \times 4-8 \mathrm{~cm}$, lâmina elíptica a elíptico-lanceolada, ápice agudo, base aguda ou obtusa, coriácea, margem plana, glabra, glândulas punctiformes pouco visíveis, nervação plana na adaxial, pouco proeminente na abaxial, nervação terciária finamente marcada; ócrea $1-1,5 \mathrm{~cm}$, base persistente, marcescente; pecíolo 1,5-2cm, glabro, inserido na base da ócrea. Racemos laxifloros, 3-8cm, raque glabra, pedicelos inclusos nas ocréolas, ca. $0,5 \mathrm{~mm}$, brácteas e ocréolas ca. $1 \mathrm{~mm}$, glabras. Flores ca. 1,5mm. Perianto frutífero 0,8-1,2cm, arredondado a sub-arredondado, bordos aderidos; pedicelos frutíferos 2-4mm compr.

Comentários: Guianas (Howard 1960). Referida pela primeira vez para o Brasil. Floresce e frutifica durante o período de fevereiro a junho. $\mathrm{Na}$ área de estudo foi coletada em altitudes entre 650 a $900 \mathrm{msnm}$.

Material examinado: BRASIL. Bahia: Andaraí, próximo Igatu, 1253'52” S 41 '18'45" W, 800-900msnm, II/1999, Miranda-Silva et al. 59 (HUEFS); Barra da Estiva, 13³8'22” S 4110'12" W, VI/1978, Vaillant 17 (RB); Jacobina, próximo Hotel Serra do Ouro, $11^{\circ} 11^{\prime} S$ $40^{\circ} 31^{\prime} \mathrm{W}, 650 \mathrm{msnm}, \mathrm{VI} / 1983$, Coradin et al. 6129 (CEN).

Material adicional examinado: BRASIL. Bahia: Jaguaquara, 12³9'39”' S 42³3' 44” W, 785msnm, II/1999, França et al. 2613 (HUEFS). Tocantins: Tocantinópolis, cachoeirinha, Arouck et al. 312 (RB).

8. Coccoloba ochreolata Wedd., Ann. Sci. Nat. III. 13: 259. 1849.

Fig. 27-31

Arbusto escandente ou liana, ramos com casca fissurada, glabros, lenticelas verrucosas, obscuras, internós maciços, curtos, $1-5 \mathrm{~cm}$ e longos $6-13 \mathrm{~cm}$. Folhas dos ramos vegetativos $10-$ $20 \times 8-15 \mathrm{~cm}$, folhas dos ramos férteis 6-14x3,5$10 \mathrm{~cm}$, lâmina oval a oblonga, ápice agudo ou obtuso, base arredondada, subcordada a cordada, margem revoluta, membranácea a coriácea, glabra, glândulas punctiformes visíveis na face abaxial, nervação impressa em ambas as faces; ócrea $0,5-3 \mathrm{~cm}$, membranácea, glabra, caduca; pecíolo $0,5-2 \mathrm{~cm}$, glabro, inserido abaixo da base da ócrea. Racemos pêndulos, $8-12 \mathrm{~cm}$, raque glabra, estriada, pedicelos inclusos nas ocréolas, brácteas escamiformes, ca. $0,5 \mathrm{~mm}$, pubescentes, ocréolas 1,5-3mm, glabras. Flores ca. $2 \mathrm{~mm}$. Perianto frutífero $0,5-1 \mathrm{~cm}$, oval, coriáceo, lobos aderidos; pedicelos frutíferos ca. $5 \mathrm{~mm}$ compr.

Comentários: ocorre na Bahia, Espírito Santo e Rio de Janeiro (Howard 1961). Coccoloba ochreolata habita as caatingas, as restingas, as florestas atlântica e amazônica (Howard 1960). $\mathrm{Na}$ área de estudo é muito comum nas matas estacionais a altitudes entre 700 e $1.000 \mathrm{msnm}$. Floresce e frutifica entre fevereiro e abril. Espécie muito próxima a Coccoloba striata, da qual difere por apresentar pecíolo inserido abai- 


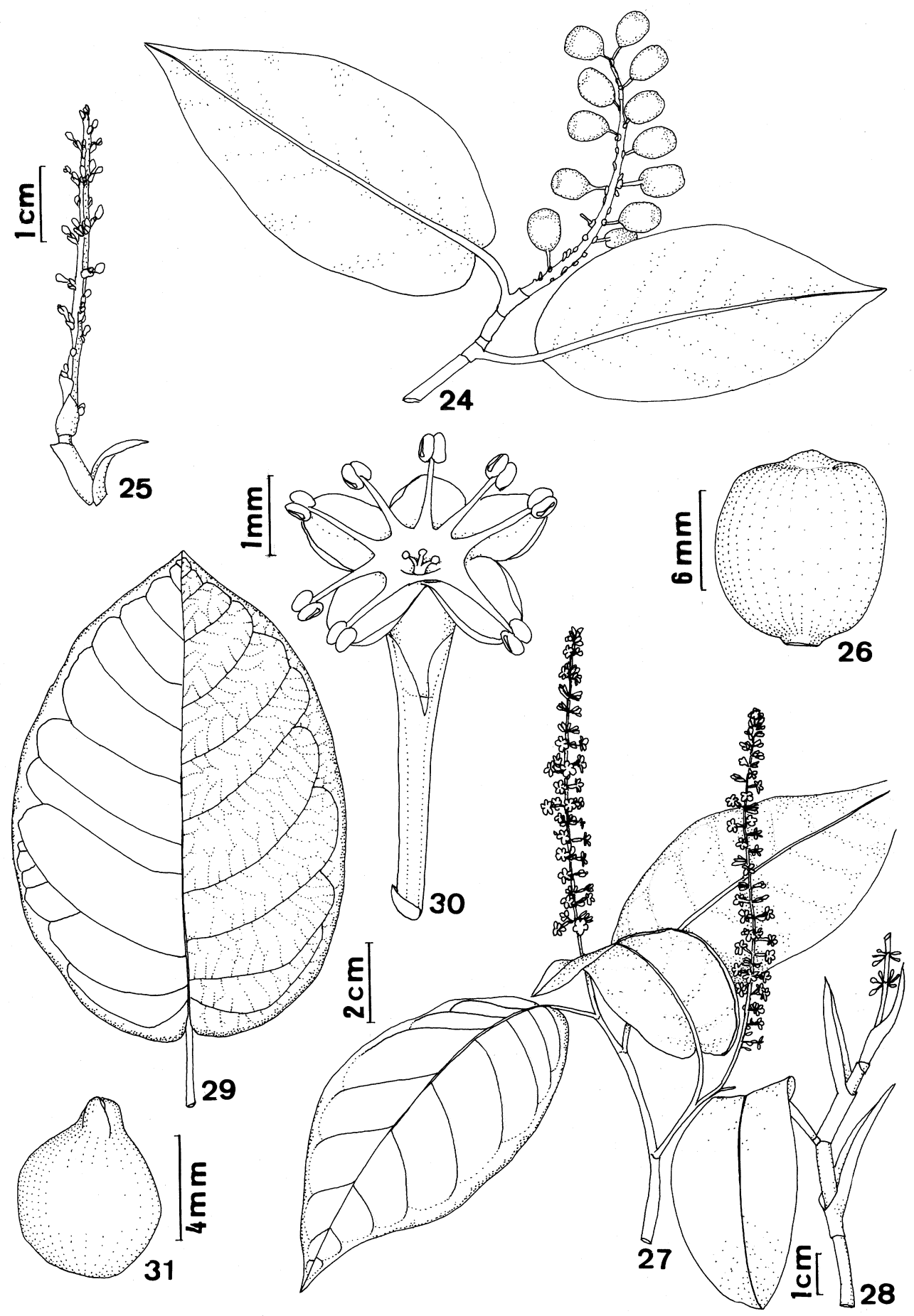

Figura 24-31. Coccoloba. 24-26. C. lucidula Benth. 24. hábito; 25. inflorescência; 26. fruto (França et al. 2613, MirandaSilva 59); 27-31. C. ochreolata Wedd. 27. hábito; 28. ápice do ramo com ócrea; 29. folha; 30. flor com ocréola e bráctea; 31. fruto (França et al. 1086, 2609). 
xo da base da ócrea.

Material examinado: BRASIL. Bahia: Jacobina, II/1993, Amorim et al. 999 (CEPEC, NY); Ibidem, III/1996, Harley et al. PCD 2654 (ALCB, HUEFS); Ibidem, IV/1996, Guedes et al. PCD 2861 (ALCB, HUEFS); Ibidem, IV/ 1996, Harley et al. PCD 2826 (ALCB, HUEFS); Ibidem, IV/1996, Woodgyer et al. PCD 2769 (ALCB, HUEFS); Lençóis, I/1997, Saar et al. PCD 4728 (ALCB, HUEFS) .

Material adicional examinado: BRASIL. Bahia: Castro Alves, Serra da Jibóia, 1251'11" S 39²8'19" W, 750msnm, XI/1994, França et al. 1086 (HUEFS).

9. Coccoloba pipericarpa Mart., Fl. Bras. 5(1): 32, pl.12. 1855.

Fig. 32-34

Arbusto com ramos escandentes, até $1,5 \mathrm{~m}$ alt., ramos com casca fissurada, glabros, internós maciços, curtos, $1-4 \mathrm{~cm}$, lenticelas verruculosas esparsas. Folhas dos ramos vegetativos não observadas, folhas dos ramos férteis $1-5,5 \times 0,5-$ $2,5 \mathrm{~cm}$, lâmina oblonga, ápice agudo ou obtuso, base obtusa, truncada a sub-cordada, coriácea, glabra, ligeiramente discolor, glândulas punctiformes na face abaxial, nervação finamente marcada em ambas as faces, nervação terciária conspícua; ócrea 4-5mm, coriácea, glabra, decídua; pecíolo ca. $5 \mathrm{~mm}$, torcido, inserido na base da ócrea. Racemos 2$4 \mathrm{~mm}$, raque costada, glabra, pedicelos $0,5-1 \mathrm{~mm}$; brácteas e ocréolas ca. $1 \mathrm{~mm}$, coriáceas. Flores 1-1,5mm. Perianto frutífero 3-8mm, coriáceo, oval a arredondado, lobos livres, imbricados; pedicelos frutíferos 1-2mm compr.

Comentários: ocorre nos Estados da Bahia, Minas Gerais e Rio de Janeiro (Howard 1961). Espécie pouco representada nas coleções dos herbários analisados.

Material examinado: BRASIL. Minas Gerais: Capelinha, 1990, Teixeira \& Brina s.n. (BHCB, HUEFS); Cristália, I/1986, Kameyama et al. CFSC 8922 (SPF); Serra do Calixto, XI/ 1984, Harley et al. CFSC 6458 (SPF).
Material adicional examinado: BRASIL. Minas Gerais: Minas Novas (Araçuai), II/1891, Martius s.n. (B).

10. Coccoloba salicifolia Wedd., Ann. Sci. Nat. 3. 13: 259. 1850.

Fig. 35-39

Arbusto ereto até $4 \mathrm{~m}$ alt.; ramos com casca fissurada, glabros, lenticelas oblongas, visíveis nos ápices dos ramos; internós maciços, curtos, $2-4 \mathrm{~cm}$. Folhas dos ramos vegetativos não observadas, folhas dos ramos férteis 2,5-8x0,5$2 \mathrm{~cm}$, lâmina lanceolada, ápice agudo, base aguda ou obtusa, margem revoluta, coriácea, glabra, glândulas não visíveis, nervação plana em ambas as faces; ócrea $0,5-1 \mathrm{~cm}$, coriácea, glabra, decídua; pecíolo $0,2-1,3 \mathrm{~cm}$, glabro, inserido abaixo da base da ócrea. Racemos densifloros, 5$7 \mathrm{~cm}$, raque glabra, costada, pedicelos ca. $1 \mathrm{~mm}$, brácteas ca. $1 \mathrm{~mm}$, glabras, ocréolas ca. $2 \mathrm{~mm}$, glabras. Flores 1,5-2mm. Perianto frutífero 5$8 \mathrm{~mm}$, oval, coriáceo, lobos livres; pedicelos frutíferos 2-5mm compr.

Comentários: ocorre nos Estados de Goiás, Minas Gerais e Rio de Janeiro (Rizzini 1986). $\mathrm{Na}$ Cadeia do Espinhaço encontra-se apenas em Minas Gerais. Floresce e frutifica entre janeiro e abril e entre julho e novembro. Ocorre nas matas ciliares e arredores, a altitudes entre $1.100-1.500 \mathrm{msnm}$.

Material examinado: BRASIL. Minas Gerais: Santana do Riacho, Parque Nacional da Serra do Cipó, Serra das Bandeirinhas, 1.400$1.500 \mathrm{msnm}, \mathrm{XI} / 1991$, Giulietti et al. CFSC 12584 (SPF); Ibidem, km 124, Rodovia Belo Horizonte-Conceição do Mato Dentro, próximo ao Ribeirão Capivara, VI/1980, Furlan \& Pirani CFSC 6221 (SPF); Ibidem, Córrego Vitalino, próximo à Fazenda Serra do Cipó, 3km NNENE da Pensão Chapéu de Sol (NNE de Cardeal Mota), 39km E de Baldim, 1.100-1.150msnm, $19^{\circ} 17^{\prime} \mathrm{S}, 43^{\circ} 35^{\prime} \mathrm{W}, \mathrm{IX} / 1990$, Steves et al. CFSC 15467 (SPF); Ibidem, km 110, córrego Vitalino, ca. 1.150msnm, IV/1995, Sztutman et al., CFSC 13901 (SPF); Ibidem, Rio Capivara, próximo à 


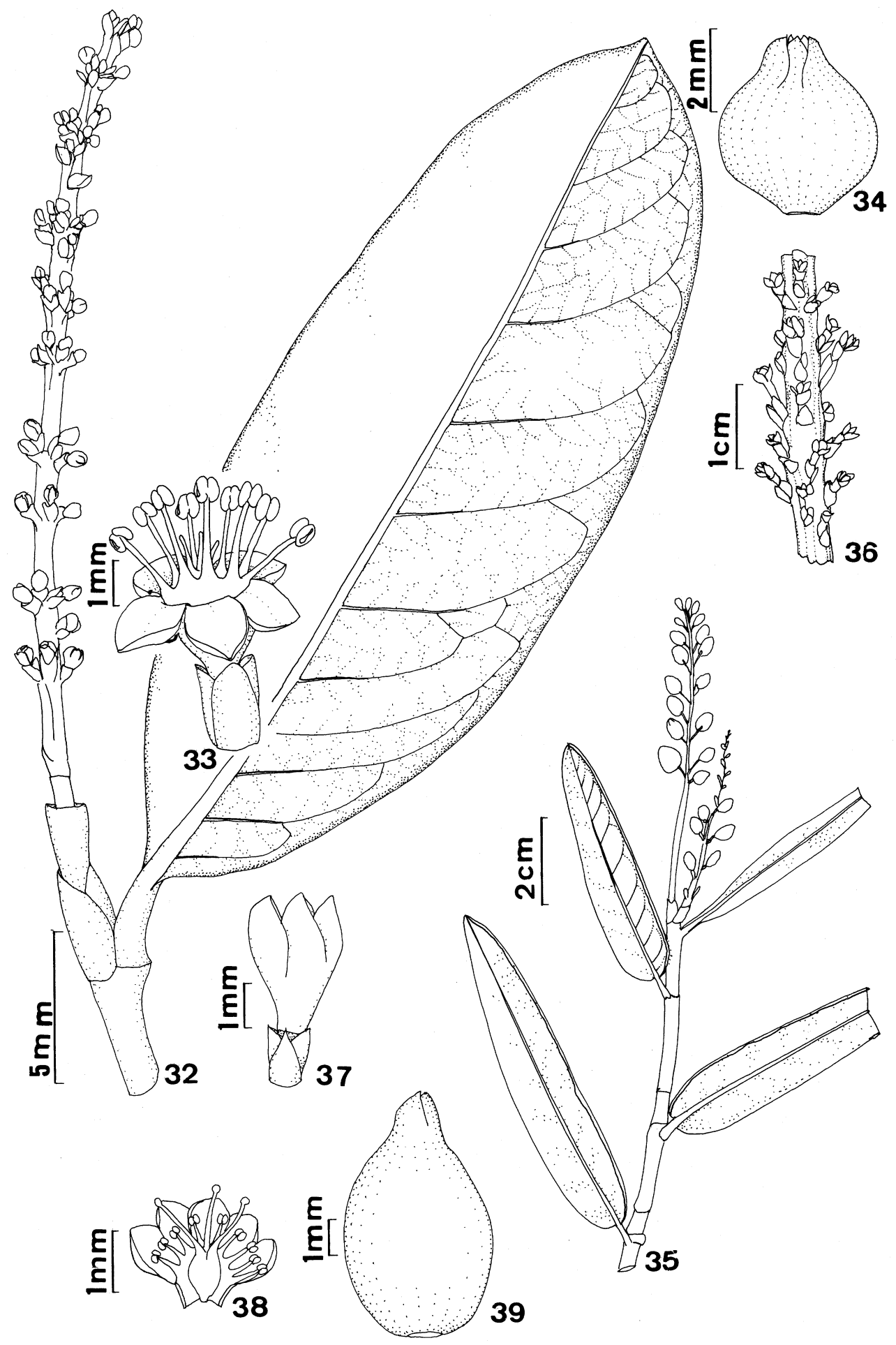

Figura 32-39. Coccoloba. 32-34. C. pipericarpa Mart. 32. hábito; 33. flor; 34. fruto (Teixeira \& Brina s.n); 35-39. C. salicifolia Wedd. 35. hábito; 36. inflorescência; 37. flor fechada; 38. flor aberta; 39. fruto (Furlan \& Pirani CFSC 6221). 
ponte da estrada para Usina, VII/1980, MelloSilva et al., CFSC 10275 (SPF); Ibidem, ca. $18 \mathrm{~km}$ após Chapéu de Sol, fazenda Cachoeira da Capivara, 19¹4'59"S, 4332'44"W, $1.300 \mathrm{msnm}, \mathrm{III} / 1995$ (SPF); Ibidem, ca. 2km após o córrego Palácio, I/1996, Souza et al. 10209 (ESA). Ibidem, km 116, ramal para cachoeira, 1.100msnm, I/1986, Martinelli et al. 11361 (RB). Ibidem, 1.200-1.300msnm, III/1964, Pereira 8930 (RB).

\section{Coccoloba scandens Casar., Nov. Stirp.} Bras. 8: 70. 1844.

Fig. 40-43

Arbusto escandente a liana; ramos com casca fissurada finamente aderida, glabros, lenticelas arredondadas a elípticas, alvas e robustas, densamente distribuídas nos ramos; internós maciços, curtos, 1-2cm, internós longos, $6-10 \mathrm{~cm}$. Folhas dos ramos vegetativos 10-20x8$15 \mathrm{~cm}$, folhas dos ramos férteis $5-16 \mathrm{x} 4-8 \mathrm{~cm}$, lâmina elíptica a oblongo-lanceolada até oval, ápice agudo ou curto-acuminado, base aguda ou obtusa, raramente subcordada, margem revoluta, coriácea, glabra na face adaxial, pubérula ou pubescente na abaxial, glândulas punctiformes visíveis na face abaxial; ócrea $0,5-1,5 \mathrm{~cm}$, coriácea, glabra, decídua; pecíolo 0,5-2cm, inserido abaixo da base da ócrea. Racemos densifloros, $6-20 \mathrm{~cm}$, brácteas ca. $1 \mathrm{~mm}$, pubérulas, ocréolas ca. 1 $\mathrm{mm}$, glabras; pedicelos 2-5mm. Flores $1-2 \mathrm{~mm}$. Perianto frutífero 0,8$1 \mathrm{~cm}$, oval a arredondado, coriáceo, lobos aderidos; pedicelos frutíferos $0,5-1 \mathrm{~cm}$ compr.

Comentários: espécie distribuída nos Estados de Goiás, Minas Gerais, Pernambuco e Rio de Janeiro (Rizzini 1986). É registrada pela primeira vez para o Estado da Bahia, onde ocorre exclusivamente na Chapada Diamantina. Coletada com frutos no mês de abril. Ocorre nas matas ciliares em forma de cipós e nos cerrados e campo rupestre, sob a forma de arbustos escandentes. $\mathrm{Na}$ área de estudo foi coletada em altitudes acima de $920 \mathrm{msnm}$.

Material examinado: BRASIL. Bahia: Bar- ra da Estiva, Estrada Barra da Estiva para Mucugê, km 7, 133' S 4122'W, 1220msnm, VI/ 1983, Coradin et al. 6418 (CEN); Lençóis, Serra da Chapadinha, 12²7'2" S 41'27'3" W, 920msnm, Melo et al. PCD 1700 (HUEFS).

Minas Gerais: Santana do Riacho, caminho para São José da Serra e Jaboticatubas, IV/1988, Menezes et al. CFSC 11076 (SPF).

12. Coccoloba schwackeana Lind. Bot. Jahrb.13: 200. 1890.

Fig. 44-47

Arbusto ereto ou arvoreta até $4 \mathrm{~m}$ alt., ramos com casca aderida, ápices pubescentes, lenticelas arredondadas, alvas, diminutas, internós maciços. Folhas dos ramos vegetativos não observadas, folhas dos ramos férteis 3,5$8,0 \times 2,5-5,5 \mathrm{~cm}$, lâmina obovado-orbicular a oblonga, ápice arredondado abrupto-acuminado ou obtuso, base cordada, subcordada a arredondada, margem plana, diminuto crenada, coriácea, glabra, pilosidade remanescente na nervura principal da face abaxial, com glândulas punctiformes diminutas visíveis na face abaxial, nervação impressa em ambas as faces; ócrea 3-5mm, coriácea, pilosa; pecíolo 3-5mm, inserido acima da base da ócrea. Racemos $5-10 \mathrm{~cm}$, raque glabra, estriada, pedicelos ca. $1 \mathrm{~mm}$., brácteas ca. 0,3 $\mathrm{mm}$, pubescentes, ocréolas 1,5-2 mm, glabras. Flores $2,5-4 \mathrm{~mm}$. Perianto frutífero 4$5 \mathrm{~mm}$, arredondado, coriáceo, lobos livres; pedicelos frutíferos ca. $3 \mathrm{~mm}$ compr.

Comentários: ocorre nos Estados da Bahia e em Minas Gerais (Rizzini 1986). Espécie muito comum nas caatingas do Estado da Bahia. Na Chapada Diamantina, ocorre a altitude de aproximadamente $1.000 \mathrm{msnm}$.

Material examinado: BRASIL. Bahia: Abaíra, 1,5 km da cidade, na entrada para Piatã, 1315'22,4"S 4140'07'W, Harley 53604 (HUEFS); Aracatu, Estrada para Brumado, III/ 1984, Bohrer 13 (HUEFS, MG); Livramento do Brumado, 35km S, IV/1991, Lewis \& Andrade 1931 (NY). Minas Gerais: Januária, Vale do Rio Peruaçu, cerrado de Judas, VII/1997, Sali- 


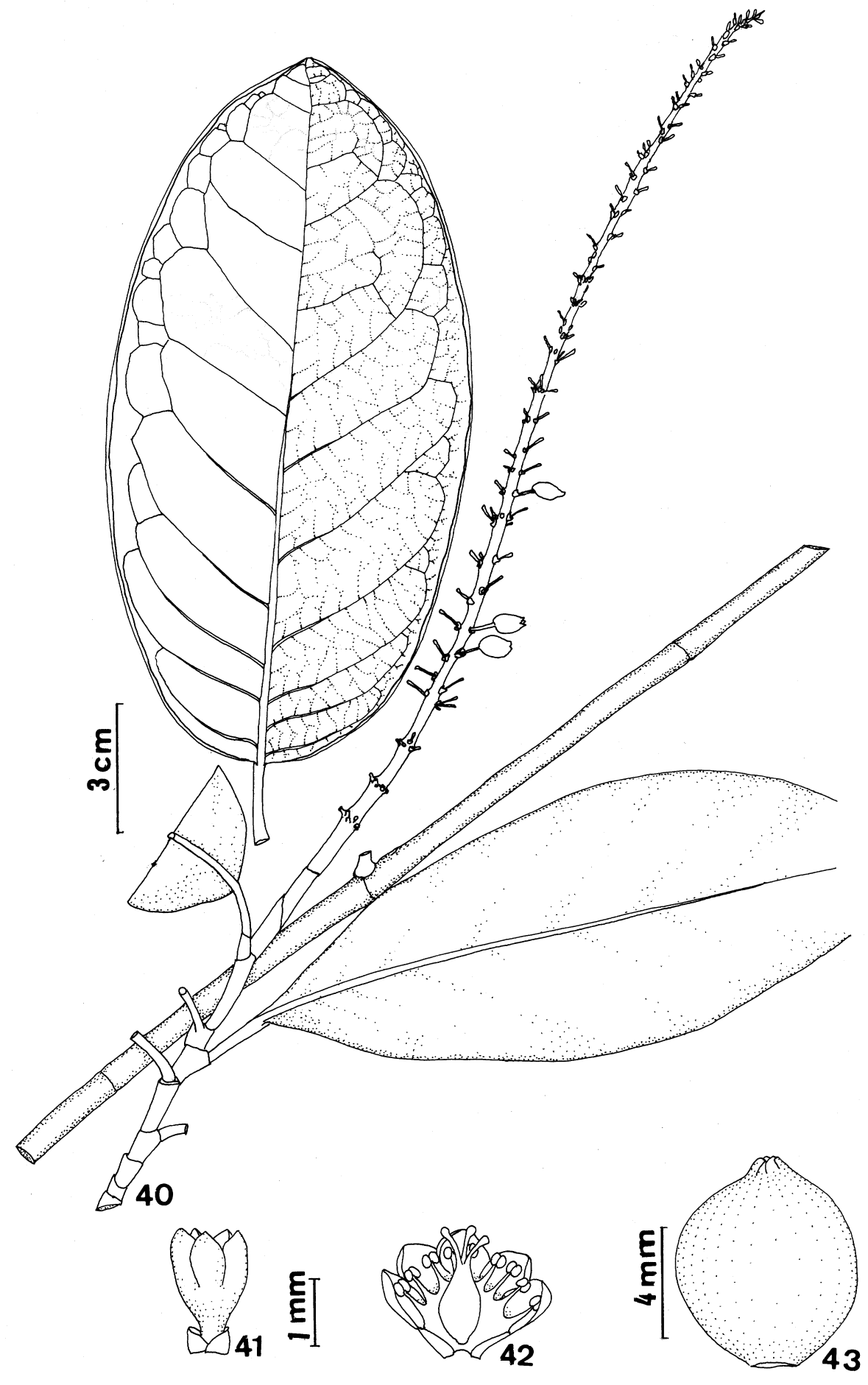

Figura 40-43. Coccoloba scandens Casar. 40. hábito; 41. flor fechada; 42. flor aberta; 43. fruto (Menezes et al. 11076, Melo et al. PCD 1700). 
no \& Stehmann 3301 (BHCB); Ibidem, Vale do Rio Peruaçu, lagoa proximo Sítio arqueológico do caboclo, VII/1997, Salino \& Stehmann 3320 (BHCB).

13. Coccoloba striata Benth., Lond. Jour. Bot. 4: 626. 1845.

Fig. 48-49

Arbusto escandente a liana; ramos com casca fissurada, glabros, lenticelas elípticas, marrons, pouco visíveis; internós maciços, curtos, $2,5-4 \mathrm{~cm}$ e longos $6-9 \mathrm{~cm}$. Folhas dos ramos vegetativos $10-20 \times 5-10 \mathrm{~cm}$, folhas dos ramos férteis 5,5-16x2,5-10cm, lâmina elíptico-obovada a elíptico-lanceolada, ápice curto-acuminado, base arredondada, subcordada a subpeltada, submembranácea a coriácea, margem revoluta, glabra a pubérula, glândulas punctiformes pouco visíveis, nervação imersa na adaxial e proeminente na abaxial; ócrea $0,5-2,5 \mathrm{~cm}$, coriácea, glabra, decídua na porção apical, base persistente escariosa; pecíolo $0,5-2,5 \mathrm{~cm}$, glabro, inserido acima da base da ócrea. Racemos densifloros, $10-15 \mathrm{~cm}$, raque pubérula, costada, pedicelos inclusos nas ocréolas, ca. $1 \mathrm{~mm}$, brácteas ca. $1,5 \mathrm{~mm}$, ocréolas ca. $2 \mathrm{~mm}$, pubérulas. Flores ca. $2 \mathrm{~mm}$. Perianto frutífero 5$6 \mathrm{~mm}$, oval, lobos aderidos; pedicelos frutíferos 2-3mm compr.

Comentários: ocorre nos Estados da Bahia, São Paulo, Rio de Janeiro e Pernambuco (Lindau 1890). Na área estudada foi coletada em botões no mês de fevereiro.

Material examinado: BRASIL. Bahia: Andaraí, estrada velha para Lençóis, 5km do entroncamento com a estrada Andaraí/BR-242, XII/1981, Carvalho et al. 1076 (CEPEC, HUEFS); Ibidem, 1244'46" S 41'20'40" W, $315 \mathrm{msnm}$, II/1999, França et al. 2635 (HUEFS).

14. Coccoloba warmingii Meisn., Symbollae 128. 1870.

Fig. 50-53

Árvore, raramente arbusto, 2-8m alt.; ra- mos com casca fissurada, glabros; internós fistulosos; lenticelas verruculosas alvas. Folhas dos ramos vegetativos $15-30 \times 8-15 \mathrm{~cm}$, folhas dos ramos férteis $8-19 \times 4,5-9 \mathrm{~cm}$; lâmina oblongoobovada a obovado-lanceolada, ápice obtuso a arredondado, sub-acuminado; base sub-cordada a truncada, ligeiramente assimétrica; coriácea, glabra, discolor; sem glândulas punctiformes; margem plana, nervação imersa na face adaxial, proeminente na face abaxial; tricomas remanescentes nas nervuras principais da face abaxial; ócrea cilíndrica, inteira, borda marcescente 1$1,5 \mathrm{~cm}$, coriácea, glabra ou pubérula, base persistente; pecíolo $1-3 \mathrm{~cm}$, glabro, inserido acima da base da ócrea. Racemos densifloros, 10$25 \mathrm{~cm}$; raque glabra, costada; pedicelos 1,5-2mm; brácteas $0,2 \mathrm{~mm}$, glabras, ocréolas ca. $1 \mathrm{~mm}$, glabras. Flores 1,5-3mm. Perianto frutífero 0,7$1 \mathrm{~cm}$, oval, coriáceo, lobos livres, imbricados; pedicelos frutíferos $0,5-1 \mathrm{~cm}$ compr.

Comentários: ocorre na Bahia, Minas Gerais, Santa Catarina, Paraná, São Paulo e Rio de Janeiro (Howard 1992). Floresce no período de fevereiro a maio.

Material examinado: BRASIL. Bahia: Iraquara, III/1980, Pinto 117 (HRB, MG); Vitória da Conquista, III/1978, Mori et al. 9413 (CEPEC); Ibidem, II/1992, Carvalho et al. 3796 (CEPEC, HUEFS, NY).

2. Polygonum L., Gen. Pl. 5: 170. 1754.

Ervas ou subarbustos, monóicos; nós radicantes, internós maciços. Folhas lanceoladas, membranáceas; ócrea tubulosa, margem truncada, geralmente persistente. Inflorescências racemosas bi ou tri-ramificadas. Flores andróginas envolvidas por ocréola; perianto 46-partido, tepalóide, conato na base; androceu 7-9 estames adnatos ao perianto; anteras dorsifixas, versáteis; glândulas nectaríferas na base dos estames; gineceu bi ou tricarpelar, 2-3 estiletes, estigmas capitados. Fruto diclésio, trígono ou lenticular; perianto frutífero membranáceo marcescente.

Comentários: gênero cosmopolita, com cer- 


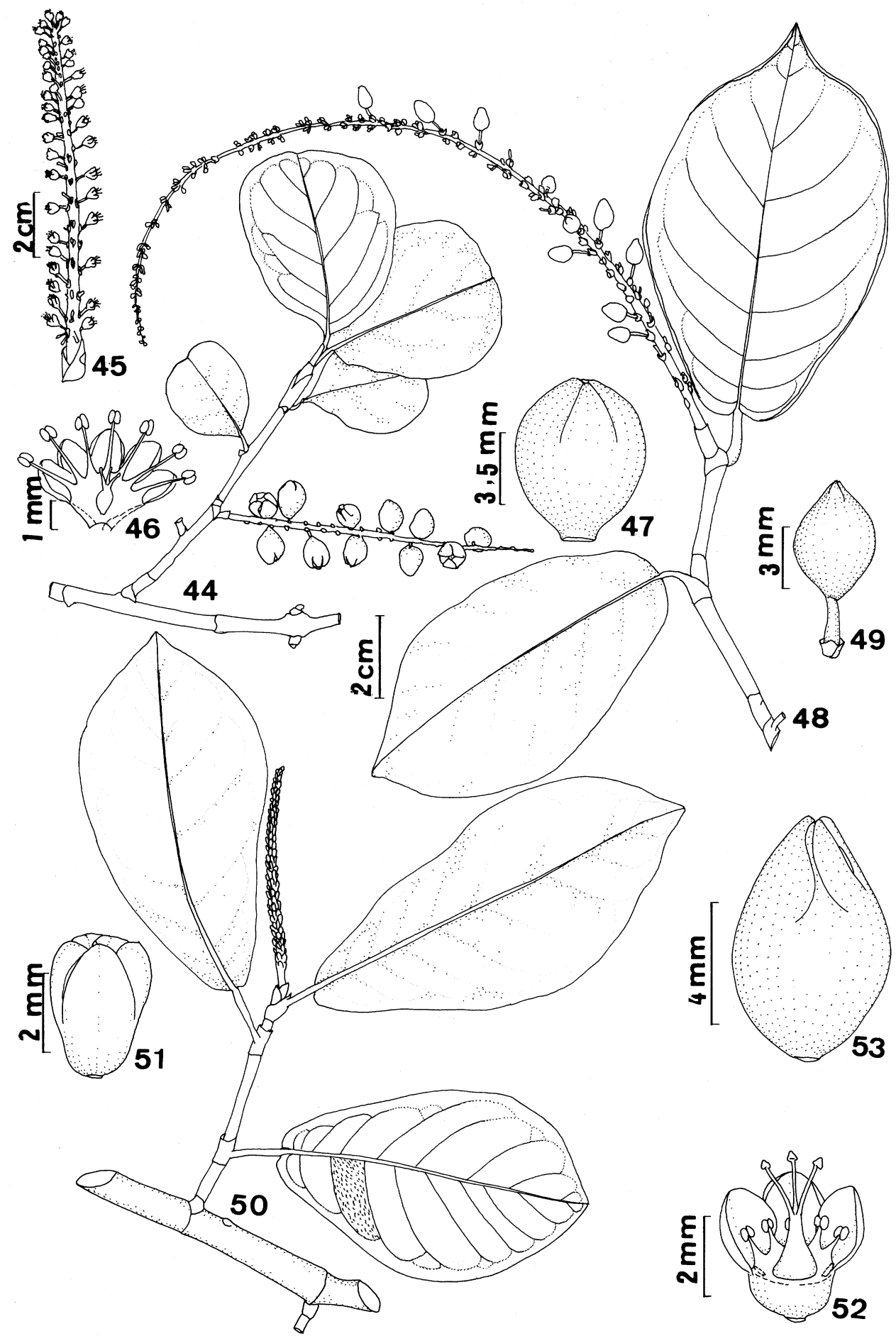

Figura 44-53. Coccoloba. 44-47. C. schwackeana Lind. 44. hábito; 45. inflorescência; 46. flor aberta; 47. fruto (Salino \& Stehmann 3301, 3320); 48-49. C. striata Benth. 48. hábito; 49. fruto (França et al. 2635); 50-51. C. warmingii Meisn. 50. hábito; 51. flor fechada; 52. flor pistilada aberta; 53. fruto (Carvalho 3796). 
ca de 200 espécies amplamente distribuídas nas regiões temperadas e tropicais de todo o mundo (Cialdella 1989). As espécies encontradas na área de estudo ocorrem nas margens de rios, lagoas e locais inundáveis. O pequeno número de amostras nos herbários não permite a definição precisa do período fenológico.

Chave para a identificação das espécies de Polygonum da Cadeia do Espinhaço

1. Folhas de base hastada, subcordada ou truncada, tricomas retrorsos presentes nas nervuras da face abaxial

5. P. meisnerianum

1. Folhas de base aguda ou atenuada, sem tricomas retrorsos

2. Fruto trígono, plantas glabras

3. Perianto frutífero com glândulas punctiformes 6.P. punctatum

3. Perianto frutífero sem glândulas 4. P. hydropiperoides

2. Fruto lenticular, plantas pubescentes

4. Ócrea com a margem franjada, revoluta 3. P. hispidum

4. Ócrea com a margem truncada, lisa

5. Perianto frutífero acrescente, margem da ócrea com tricomas longos, setosos 1. P. acuminatum

5. Perianto frutífero não acrescente, margem da ócrea com tricomas curtos, ciliados

2. P. ferrugineum

1. Polygonum acuminatum Kunth, Nov. Gen. et Sp. Pl. 2:178. 1817.

Fig. 54-57

Erva até $1,5 \mathrm{~m}$ alt., ramos estrigosos. Folhas 8-15x1,5-3cm, lâmina lanceolada a oval-lanceolada, ápice agudo longo-atenuado, base arredondada ou obtusa, tomentosa, raro glabra; ócrea 1-3,5cm, pubescente, raro glabra, margem com longos pelos setosos, pecíolo até $1 \mathrm{~cm}$. Racemos densifloros, pedúnculos pubescentes; ocréolas cônicas, margem ciliada. Flor 3-4mm, glândulas nectaríferas bem desenvolvidas, amarelas. Fruto lenticular, faces convexas, 2$3 \mathrm{~mm}$, perianto frutífero sem glândulas, lobos acrescentes.

Comentários: ocorre nas regiões sul, sudeste, centro-oeste e nordeste brasileiro (Melo 1991). Difere de Polygonum ferrugineum por apresentar pubescência nas margens das ócreas, ocréolas e pedúnculos.

Material examinado: BRASIL. Bahia: Lençóis, Remanso/Marimbus, pântano do Rio Santo Antônio, 12³9'S 4119'W, 380msnm, I/1997, Stannard et al. PCD 4646 (ALCB, HUEFS).

\section{Polygonum ferrugineum Wedd., Ann.} Sci. Nat. 3, 13: 252. 1850.

Fig. 58-60

Erva ou subarbusto até $1 \mathrm{~m}$ alt., ramos glabros. Folhas $10-20 \times 3-4,5 \mathrm{~cm}$, lâmina ovallanceolada, ápice agudo, raro acuminado, base decurrente até $2 / 3$ do pecíolo, piloso-lanosa, glabrescente, com glândulas punctiformes marrons, viscosas; ócrea 1-3cm, glabra ferruginosa, margem plana. Racemos densifloros, pedúnculos glabros; ocréolas cônicas, margem glabra. Perianto 4-5 partido, 3-4mm, glândulas nectaríferas subdesenvolvidas. Fruto lenticular sub-arredondado, faces ligeiramente côncavas, 2,5-4mm, perianto frutífero com pontos glandulosos esparsos, lobos não acrescentes.

Comentários: ocorre no Paraná, Goiás, Mato Grosso do Sul, Distrito Federal, Bahia, Ceará e Amazonas (Melo 1991). É possível encontrar populações de Polygonum ferrugineum e $P$. hispidum crescendo juntos na mesma lagoa. P. hispidum apresenta ócreas com margem foliácea franjada e revoluta e a planta é toda híspido-pubescente, enquanto em $P$. ferrugineum a ócrea tem margem ferrugínea, truncada e nunca revoluta e a planta é glabrescente. Indivíduos jovens apresentam pubescência alva que dá o aspecto verdeacinzentado à população. Esta pubescência tende a cair de forma que, na maturidade, a maioria dos indivíduos é completamente glabra.

Material examinado: BRASIL. Bahia: 


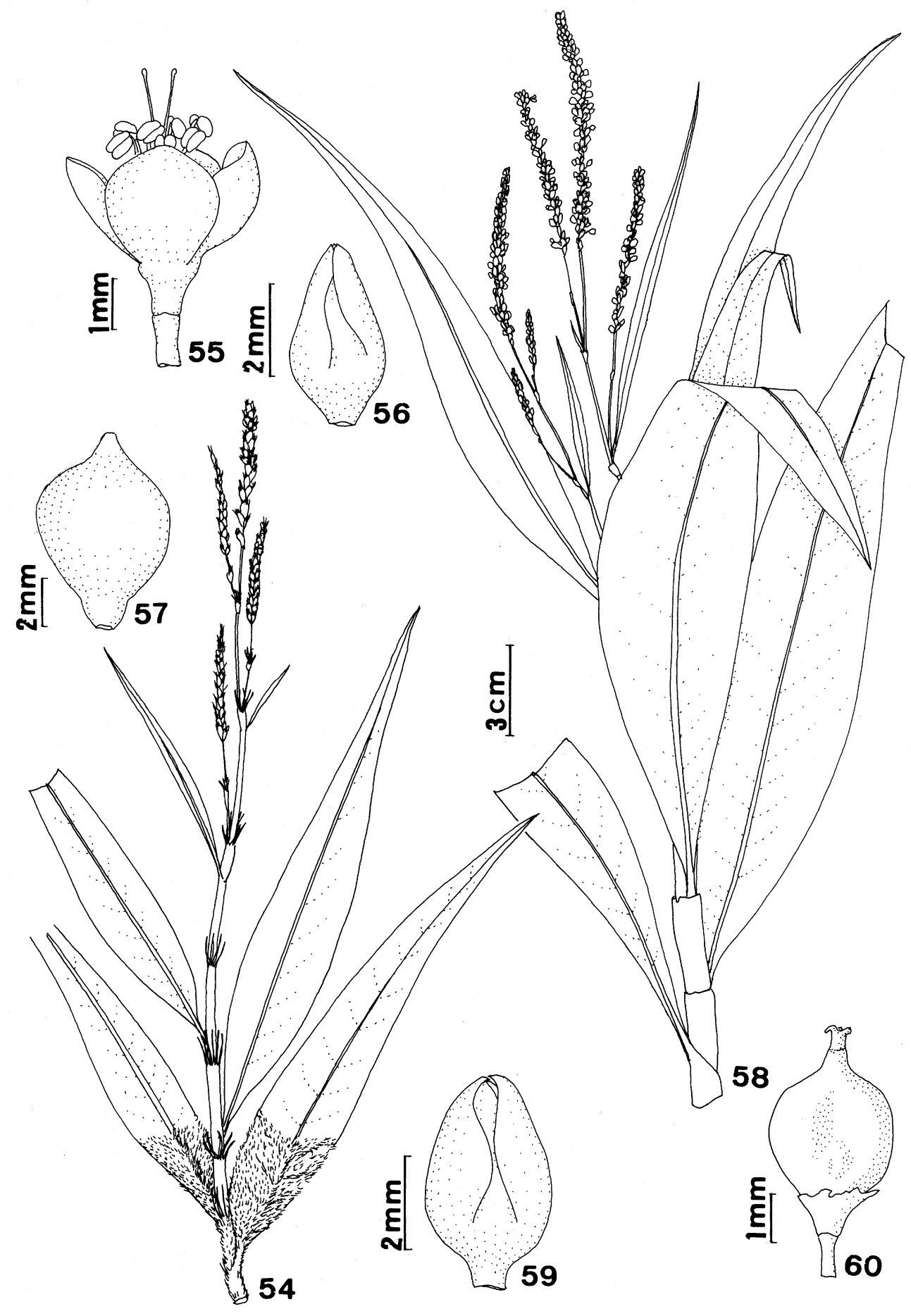

Figura 54-60. Polygonum. 54-57. P. acuminatum Kunth 54. hábito; 55. flor; 56. fruto; 57. fruto sem o exocarpo (Stannard et al. PCD 4646); 58-60. P. ferrugineum Wedd. 58. hábito; 59. fruto; 60. fruto sem o exocarpo (França et al. 2456). 
Jacobina, margem do rio Itapicuru-mirim, 11'11'22" S 40³0'29" W, 450msnm, XI/1997, França et al. 2456 (HUEFS); Paramirim, Barragem do Zabumbão, 13²6'6”'S 42¹2'39'W, 670msnm, II/1997, Guedes et al. PCD 5159 (HUEFS).

3. Polygonum hispidum Kunth, Nov. Gen. Sp. Pl. 2:178. 1817.

Fig. 61-63

Erva ou subarbusto até $1 \mathrm{~m}$ alt.; ramos estrigoso-pubescentes. Folhas 12-20x4-8cm, lâmina oval-lanceolada, ápice atenuado, base decurrente, híspido-pubescente, glândulas punctiformes em ambas as faces; ócrea $2 \mathrm{~cm}$, foliácea, margem franjada, revoluta, híspidopubescente; pecíolo $2 \mathrm{~cm}$, pubescente. Racemos densifloros, pedúnculos estrigosos; ocréolas cônicas, pubescentes. Flor 3-4mm, perianto com glândulas esparsas, glândulas nectaríferas desenvolvidas. Fruto lenticular, 2-4,5mm, faces côncavas, perianto frutífero sem glândulas, lobos não acrescentes.

Comentários: ocorre no Ceará, Piauí, Pernambuco e Minas Gerais (Cialdella 1989). Facilmente se reconhece esta espécie pelas margens franjadas e revolutas da ócrea e pela pubescência dos ramos e folhas.

Material examinado: BRASIL. Bahia: Jacobina, margem do Rio Itapicuru-mirim, 11'11'22" S 40³0'29” W, 450msnm, XI/1997, França et al. 2455 (HUEFS); Ibidem, Catuaba, 11'10'22" W 40³2'44” W, 727msnm, VII/1996, Giulietti et al. PCD 3388 (HUEFS); Rio de Contas, Distrito de Marcolino Moura, $13 \mathrm{~km}$ na estrada Rio de Contas/Jussiape, Reservatório de Água, 1335'58'’S 4144'6”'W, 650msnm, II/ 1999, Miranda-Silva et al. (HUEFS).

4. Polygonum hydropiperoides Michx., Fl. Bor. Amer. 1: 239. 1803.

Fig. 64-66

Erva até $40 \mathrm{~cm}$ alt.; ramos glabros. Folhas 5-9x0,8-1,2cm, lâmina lanceolada, ápice e base atenuados, margens e nervuras ciliadas, face abaxial freqüentemente com pontos glandulosos brancos, opacos; ócrea 1-1,5cm, margem ciliada; pecíolo curto, $2-5 \mathrm{~mm}$. Racemos $6-7 \mathrm{~cm}$, pedúnculos glabros, ocréolas cônicas, margem ciliada. Flor 2-3mm, glândulas nectaríferas pouco desenvolvidas. Fruto trígono $1-2,5 \mathrm{~mm}$, liso e brilhante, perianto frutífero sem glândulas, lobos não acrescentes.

Comentários: espécie bem distribuída nas regiões sul, sudeste e centro-oeste do Brasil (Melo 1991). Difere de Polygonum punctatum por não apresentar glândulas no perianto frutífero.

Material examinado: BRASIL. Bahia: Morro do Chapéu, leito pedregoso do Rio Ven-

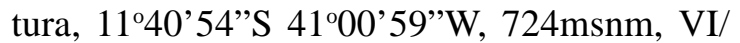
1996, Harley et al. PCD 3108 (ALCB, HUEFS); Ibidem, Povoado de Ventura, III/1997, Lughadha et al. PCD 5017 (HUEFS);

5. Polygonum meisnerianum Cham. \& Schl., Linnaea 3: 40. 1828.

Erva ca. $50 \mathrm{~cm}$ alt., ramos glabros ou hirsutopubescentes, tricomas caducos. Folhas 3-10x $0,5-1,5 \mathrm{~cm}$, lâmina linear-lanceolada, ápice longo-atenuado, base hastada, truncada a subcordada, face adaxial glabra, face abaxial com tricomas retrorsos restritos à nervura central, sem glândulas evidentes; ócrea 1-1,5cm, membranácea; pecíolo curto, ca. $2 \mathrm{~mm}$. Racemos subdicotômicos, ca. $10 \mathrm{~cm}$, paucifloros, tricomas glandulares presentes nos ramos distais dos pedúnculos, ocréolas cônicas ca. $2 \mathrm{~mm}$, margem ciliada. Flor ca. $3 \mathrm{~mm}$, glândulas nectaríferas pouco desenvolvidas. Fruto oval, 2-2,5mm, perianto frutífero sem glândulas, lobos acrescentes.

Comentários: ocorre nos Estados de São Paulo, Paraná, Rio Grande do Sul, Santa Catarina, Distrito Federal e Minas Gerais (Park 1988). Registrada pela primeira vez no Estado da Bahia. Espécie de fácil reconhecimento pelos tricomas retrorsos presentes nas nervuras das folhas e nos ramos.

Material examinado: BRASIL. Bahia: Cas- 
cavel, entre Lagoa Encantada e Cascavel, $13^{\circ}$ 18' 4'S 41 '20'45'W. 949msnm, III/1999, Harley et al. 53587 (HUEFS). Minas Gerais: Serra do Espinhaço, ca. 35km NE de Francisco de Sá, estrada para Salinas. 1.100msnm, II/1969, Irwin et al. 23309 (HUEFS); Ouro Preto, Pico do Itacolomi, ca. $3 \mathrm{~km} \mathrm{~S}$ de Ouro Preto, 1.650msnm, II/1971, Irwin et al. 29565 (UB).

6. Polygonum punctatum Elliott, Sketch. Bot. D. Carol. Geogr. 1: 455. 1817.

Fig. 67-69

Erva até $50 \mathrm{~cm}$ alt.; ramos glabros. Folhas 6-12x1,5-4cm, lâmina lanceolada a ovallanceolada, ápice atenuado, base aguda, glabra, glândulas punctiformes em ambas as faces, margem ciliada; ócrea 1-1,5cm, margem ciliada; pecíolo 1-1,5cm. Racemos 6-11 cm, laxifloros, pedúnculos glabros; ocréolas cônicas, afuniladas, glabras. Flor 2-3mm, perianto com glândulas punctiformes; glândulas nectaríferas pouco desenvolvidas. Fruto 1,5-2mm, trígono, liso e brilhante, perianto frutífero punctato-glanduloso, lobos não acrescentes.

Comentários: no Brasil encontra-se distribuída nos Estados do Pará, Maranhão, Bahia, Distrito Federal, Goiás, Mato Grosso, Mato Grosso do Sul, Rio de Janeiro, Minas Gerais, São Paulo, Rio Grande do Sul, Paraná e Santa Catarina (Melo 1991). Floresce e frutifica o ano todo.

Material examinado: BRASIL. Bahia: Jussiape, III/1977, Harley 20027 (CEPEC, HRB, MBM); Morro do Chapéu, Povoado de Ventura, III/1997, Lughadha et al. PCD 6013 (ALCB, HUEFS); Rio de Contas, povoado de Mato Grosso, IV/1997, 13²7'58'S 41050'17'W, $1.455 \mathrm{msnm}$, Harley \& Giulietti 28647 (HUEFS). Minas Gerais: Lapinha, Serra do Espinhaço, ca. $19 \mathrm{~km}$ de Sêrro, estrada para Diamantina, II/1968, Irwin et al. (UB).

3. Rumex L. Sp. Pl. 1: 3345. 1753.

Ervas ou subarbustos, perenes, monóicos ou dióicos; ramos glabros, medula maciça. Folhas lanceoladas, membranáceas, margem plana; ócrea membranácea, marcescente, glabra. Racemos simples ou ramificados, folhosos, fascículos espaçados irregularmente; pedicelos articulados; ocréolas hialinas, marcescentes. Flores unissexuadas, rudimento do sexo abortado presente, perianto 6-partido, glândulas nectaríferas ausentes; flor estaminada com perianto indistinto, anteras rimosas basifixas; flor pistilada com 3 peças externas menores que as 3 internas, gineceu trígono-ovalado, estiletes livres, estigmas plumosos. Fruto diclésio, perianto frutífero membranáceo, protuberância sobre a face externa das alas (calo) desenvolvido nas 3 peças internas ou apenas em uma, raro ausente. Comentários: gênero com cerca de 100 espécies amplamente distribuídas, mas pouco representadas nas regiões tropicais (Graham \& Wood Jr. 1965).

1. Rumex crispus L. Sp. Pl. 1: 3345. 1753. Fig. 70-72

Ervas ou subarbustos, dióicos, até $80 \mathrm{~cm}$ alt., pouco ramificados; ramos eretos, estriados. Folhas 10-30x6-10cm, lâmina oblongo-lanceolada, ápice agudo ou obtuso, base obtusa, margem ondulada, glabra; ócrea $1-5 \mathrm{~cm}$, glabra; pecíolo achatado na base, $3-5 \mathrm{~cm}$. Racemos múltiplos, eretos, densifloros, pedicelos filiformes, patentes, $2-7 \mathrm{~mm}$, ocréolas hialinas, escamiformes, marcescentes. Flores 2-3mm, verticilo externo menor, conato na base, interno, maior, margens inteiras, flores estaminadas com 6 estames iguais, filetes curtos, anteras basifixas; flores pistiladas com ovário trígono, 3 estiletes, estigmas plumosos. Fruto diclésio, 3-4mm, trígono-ovalado, alas cordado-ovaladas, membranáceas, de bordos inteiros, calo dorsal mais desenvolvido em uma das alas; pedicelos frutíferos 4-6mm.

Comentários: nativa da Europa (Holm et al. 1977). Adventícia em todo o mundo (Palacios 1987). Coletada com frutos no mês de abril.

Material examinado: BRASIL. Bahia: Rio de Contas, IV/1997, Harley \& Giulietti 28646 (HUEFS). 


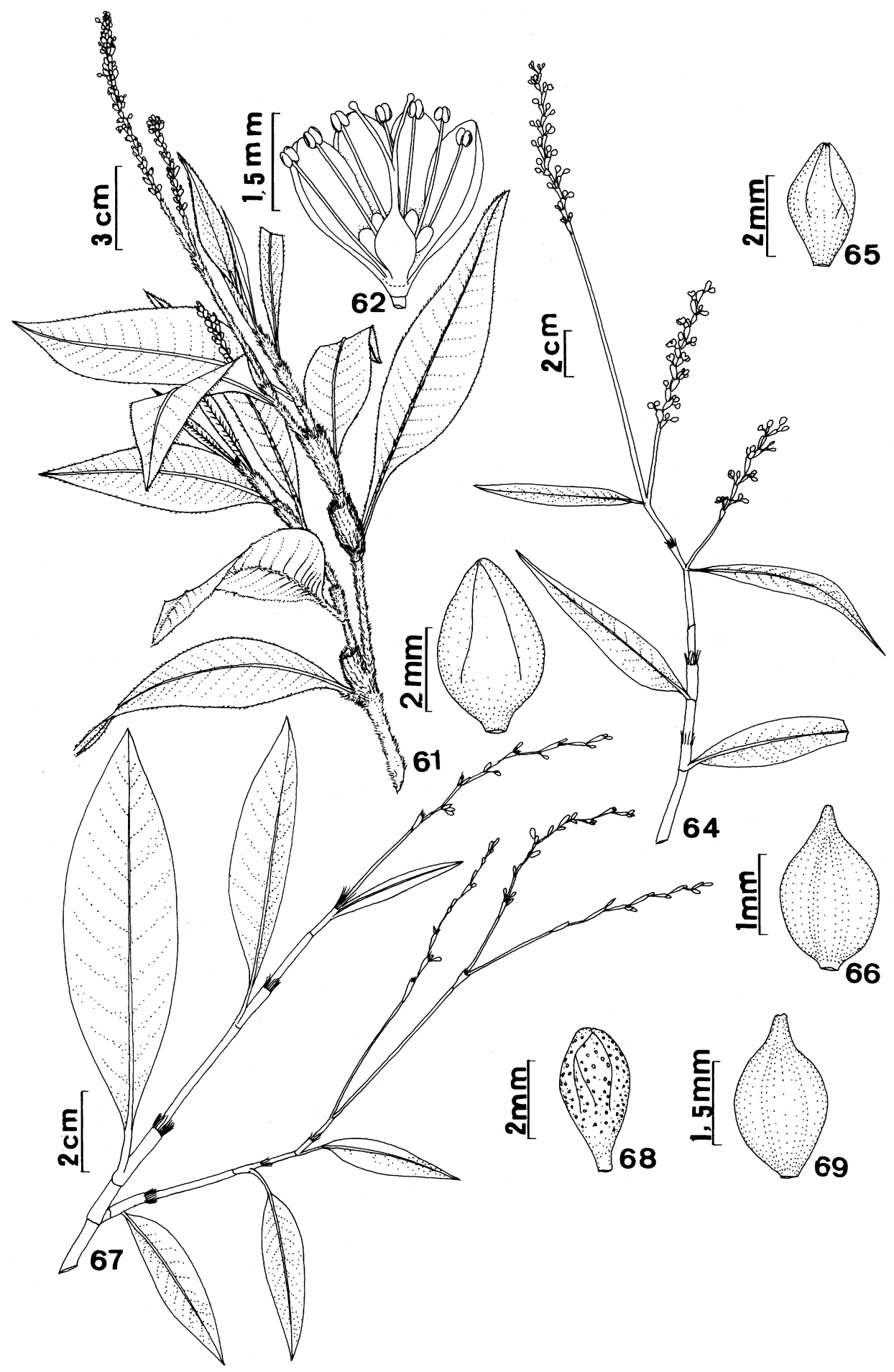

Figura 61-69. Polygonum. 61-63. P. hispidum Kunth 61. hábito; 62. flor; 63. fruto (Harley et al. PCD 3388); 64-66. P. hydropiperoides Michx. 64. hábito; 65. fruto; 66. fruto sem o exocarpo (Harley et al. PCD 3108); 67-69. P. punctatum Ell. 67. hábito; 68. fruto; 69. fruto sem o exocarpo (Harley et al. 28647). 
Material adicional examinado: BRASIL. Distrito Federal: Plano Piloto, Melo 871 (CEN, UB).

4. Ruprechtia C. A . Meyer, Mém. Acad. Imper. St. Petersb.6: 148. 1848.

Arbustos ou árvores de até 20m alt., dióicos; ramos glabros ou pubescentes, medula maciça. Folhas oblongas, elípticas ou lanceoladas, coriáceas a subcoriáceas, margem inteira ou crenulada, glabras ou pubescentes; ócrea caduca; pecíolo achatado dorsalmente. Racemos ramificados, subpaniculados, flores em fascículos envoltos por brácteas. Perianto 6-partido, conato na base, flor estaminada com perianto indistinto, 9 estames, filetes conatos na base, anteras dorsifixas, versáteis; flor pistilada com 3 pétalas atrofiadas. Fruto pseudosâmara, perianto frutífero membranáceo, formando um tubo, encobrindo parcialmente o pericarpo, lacínios acrescentes.

Comentários: gênero exclusivamente americano, com a maioria das espécies ocorrendo nos trópicos. O maior número de espécies ocorre na América do Sul, cerca de 13 no total (Cocucci 1961).

1. Ruprechtia apetala Wedd., Ann. Sci. Nat. Sér. 3. 13: 268. 1849.

Fig. 73-75

Árvore ou arbusto de 3,5-12m alt.; ramos com casca acinzentada, enegrecida, lenticelas punctiformes, alvas, esparsas. Folhas 4,5-12x2,5$7,5 \mathrm{~cm}$, lâmina oblonga a elíptica, coriácea, ápice obtuso a arredondado, raramente subacuminado; base aguda, obtusa ou arredondada, margem crenulada; face adaxial com nervação impressa, pubescência esparsa, raro totalmente glabra, face abaxial com nervação proeminente, pubescência alva, densa; ócrea caduca; pecíolo 0,3-1 cm. Racemos múltiplos, subpaniculados, densifloros, raque densamente pubescente, brácteas escamiformes, pubescentes. Flores estaminadas 1-2mm, flores pistiladas 2-6mm, pétalas reduzidas, filiformes, ca. $2 \mathrm{~mm}$. Fruto 2-
$3 \mathrm{~cm}$, tubo $7 \mathrm{~mm}$, aberto acima de $2 / 3$, externamente estrigoso, alas espatuladas, 2-2,6x5-8mm, esparsamente pubescentes.

Comentários: ocorre na Argentina e sul da Bolívia (Cocucci 1961). Coletada com frutos no mês de março.

Material examinado: BRASIL. Bahia: Paramirim, III/1981, Silva 199 (CEPEC, HUEFS, UB); Rio de Contas, Estrada Rio de

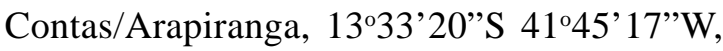
783msnm, II/1999, Leite et al. 10 (HUEFS).

5.Triplaris Loefl. ex L. Gen. Pl.: 256. 1758.

Árvores de 2-20m alt., dióicas; ramos pubescentes, medula fistulosa. Folhas lanceoladas, glabras ou pubescentes, margem plana, sem glândulas; pecíolo achatado; ócrea caduca. Racemos paniculados, densifloros, brácteas ovado-triangulares, pubescentes externamente. Flores estaminadas com perianto 6partido, cilíndrico ou campanulado; estames 6-9, filetes livres entre si; flores pistiladas com 3 peças externas conatas na base, 3 internas, rudimentares, despigmentadas. Fruto pseudosâmara, perianto frutífero, membranáceo, lacínios petalóides acrescentes.

Comentários: gênero de distribuição neotropical (Brandbyge 1986).

1. Triplaris gardneriana Wedd., Ann. Sci. Nat. III. 13: 265. 1849.

Fig. 76-80

Árvore 4-15m alt.; ramos glabros, estriados, casca marrom, enegrecidas, lenticelas elípticas a arredondadas, alvas, esparsas. Folhas ovallanceoladas a elípticas, $9-14 \times 3-5 \mathrm{~cm}$, ápice agudo, base arredondada freqüentemente assimétrica, margem plana, raramente ondulada, coriácea, face adaxial glabra a esparsamente pubescente, face abaxial pubescente, nervação marcada nas duas faces; ócrea caduca; pecíolo 1-1,5cm, achatado, glabrescente. Inflorescências paniculados, densifloras; brácteas 1-1,5mm, densamente tomentosas, bractéolas $3-5 \mathrm{~mm}$, estrigosas externamente. Perianto $3-5 \mathrm{~mm}$, 


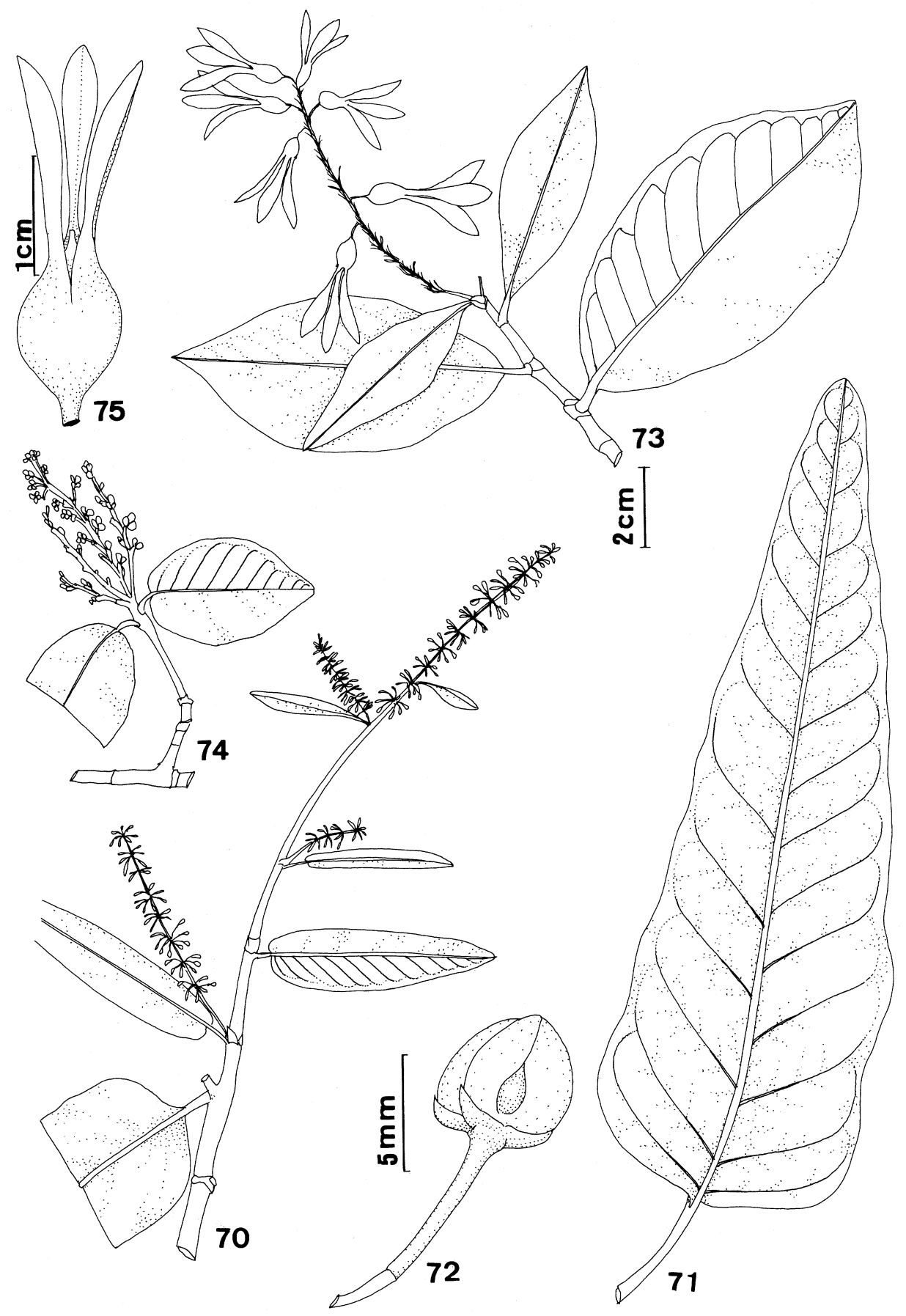

Figura 70-75. Rumex e Ruprechtia. 70-72. Rumex crispus. 70. hábito; 71. folha basal; 72. fruto (Harley \& Giulietti 28646); 73-75. Ruprechtia apetala Wedd. 73. hábito; 74. ramo da planta masculina; 75. fruto (Leite et al. 10). 


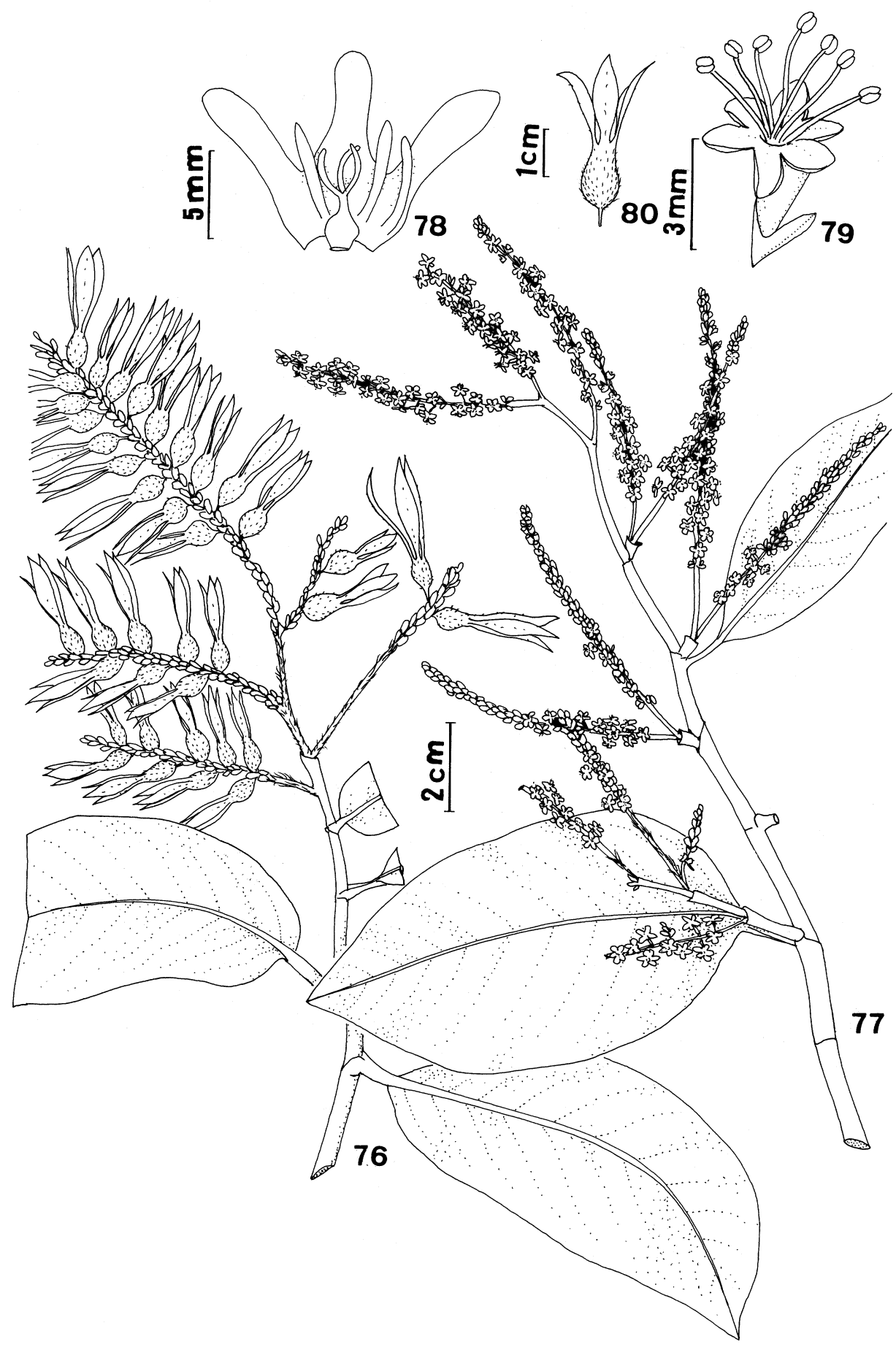

Figura 76-80. Triplaris gardneriana Wedd. 76. hábito, planta feminina; 77. planta masculina; 78. flor pistilada; 79. flor estaminada; 80. fruto (Hatschbach \& Silva 50483). 
conato na base até $2-3,5 \mathrm{~mm}$, tubo pubescente externamente; estames 6-9, exsertos. Flores femininas com brácteas de $5-10 \mathrm{~mm}$, tomentosas externamente, tubo do perianto oval a campanulado $0,5-1 \mathrm{~cm}$, externamente pubescente; pétalas lineares, reduzidas, $1-1,5 \mathrm{~cm}$, glabras. Fruto pseudosâmara, $2,5-4,5 \mathrm{~cm}$, exocarpo pubescente, alas espatuladas.

Comentários: no Brasil ocorre nos Estados de Pernambuco, Ceará, Goiás, Maranhão, Alagoas, Bahia, Piauí, Mato Grosso, Minas Gerais e Paraná (Brandbyge 1986). Coletada com frutos no mês de setembro.

Material examinado: BRASIL. Bahia: Campo Formoso, IX/1961, Orlandi 521 (ALCB, CEPEC, HRB).

Material adicional examinado: BRASIL. Bahia: Xique-Xique, VI/1996, Guedes et al. PCD 2946 (HUEFS).

\section{Referências bibliográficas}

Barroso, G. M.; Guimarães, E. F.; Ichaso, C. L. F.; Costa, C. G. \& Peixoto, A. L. 1978. Sistemática de angiospermas do Brasil, v. 1, Livros técnicos e científicos, Rio de Janeiro; Editora da Universidade de São Paulo, São Paulo.

Brandbyge, J. 1986. A revision of the genus Triplaris (Polygonaceae). Nordic Journal of Botany 6: 345 370.

Brandbyge, J. 1990. The diversity of micromorphological features in the genus Coccoloba (Polygonaceae). Nordic Journal of Botany 10: 2544.

Cialdella, A. M. 1989. Revisión taxonomica de las espécies argentinas de Polygonum s. 1. (Polygonaceae). Darwiniana 29(1-4):179-246.

Cocucci, A . E. 1961. Revision del genero Ruprechtia (Polygonaceae). Kurtiziana 1: 217-269.

Davis S. D.; Heywood, V. H.; McBride, O. H.; VillaLobos, J. \& Hamilton, A. C. (Eds.). 1997. Centres of plant diversity: a guide and strategy for their conservation. V.3 WWF/IUCN, Cambridge.

Graham, S. \& Wood Jr., C. E. 1965. The genera of Polygonaceae in the southeastern United States. Journal of the Arnold Arboretum 46(2): 91-121.

Harley, R. M. \& Simmons, M. 1980. Towards a checklist of the flora of Bahia. Royal Botanic Gardens, Kew. 250p.
Holm, L. G.; Plucknett, D. L.; Pancho, V. J. \& Herberger, J. P. 1977. The world's worst weeds: distribution and biology. Univ. Press. Hawaii, Honolulu.

Holmgren, P. K.; Holmgren, N. H. \& Barnett, L. C. 1990. Index Herbariorum, part. I. The Herbaria of the world. $8^{\mathrm{a}}$ ed. New York Botanical Garden, New York.

Howard, R. A . 1960. Studies in the genus Coccoloba, IX. A critique of the South America species. Journal of the Arnold Arboretum 41(4):213-258.

Howard, R. A . 1961. Studies in the genus Coccoloba, $X$. New species and a summary of distribution in South America. Journal of the Arnold Arboretum 42(1):87-95.

Howard, R. A. 1992. Collected notes on Coccoloba L. (Polygonaceae). Brittonia 44: 356-367.

Howard, R. A. 1995. Polygonaceae. 542 Pp. In: Stannard, B. L. (Ed.). Flora of the Pico das Almas, Chapada Diamantina - Bahia, Brazil. Royal Botanic Garden, Kew.

Lindau, G. 1890. Monographia generis Coccolobae. In: Engler, Botanische Jahrbucher fuer 13: 1-229.

Melo, E. 1991. O gênero Polygonum L. (Polygonaceae) no Estado do Paraná, Brasil. Dissertação de Mestrado. Universidade Federal do Paraná, Curitiba.

Palacios, R. 1987. Polygonaceae. Pp. 69-89. In: A . Burckart. Fl. Ilustrada da Provincia de Entre Rios (Argentina). INTA (Instituto Nacional de Tecnologia Agropecuária) Coleccion Cientifica VI(3).

Park, C. 1988. Taxonomy of Polygonum Section Echinocaulon (Polygonaceae). Memoirs of the New York Botanical Garden 47: 1-82.

Ribeiro, K. T. 1997. Padrões de abundância de Coccoloba cereifera (Polygonaceae). Dissertação de Mestrado. Universidade Federal de Minas Gerais, Belo Horizonte.

Rizzini, C. M. 1978. Revisão monográfica do gênero Coccoloba no Brasil. I. Espécies da restinga. Rodriguésia 46: 127-145.

Rizzini, C. M. 1986. Contribuição ao estudo do gênero Coccoloba (Polygonaceae). Espécies campestres. Dissertação de Mestrado. Universidade Federal do Rio de Janeiro, Rio de Janeiro.

Spjut, R. W. 1994. A systematic treatment of fruit types. Memoirs of the New York Botanical Garden 70: 1-182. 